\title{
Research on Rheological Properties of High-Percentage Artificial RAP Binder with WMA Additives
}

\author{
Weiying Wang $\mathbb{D}^{1}$ Songchang Huang, ${ }^{1}$ Yongchun Qin, ${ }^{1}$ Yiren Sun, ${ }^{2}$ Rui Dong, \\ and Jingyun Chen $\mathbb{D}^{2}$ \\ ${ }^{1}$ Key Laboratory of Transport Industry of Road Structure and Material, Research Institute of Highway Ministry of Transport, \\ Beijing 100088, China \\ ${ }^{2}$ School of Transportation and Logistics, Dalian University of Technology, Dalian 116024, China \\ ${ }^{3}$ Qilu Transportation Development Group Co., Ltd., Jinan 250000, China
}

Correspondence should be addressed to Jingyun Chen; chenjy@dlut.edu.cn

Received 30 March 2020; Revised 10 June 2020; Accepted 25 June 2020; Published 6 August 2020

Guest Editor: Meng Guo

Copyright $\odot 2020$ Weiying Wang et al. This is an open access article distributed under the Creative Commons Attribution License, which permits unrestricted use, distribution, and reproduction in any medium, provided the original work is properly cited.

With the development of pavement recycling technology, the requirement of reclaimed asphalt pavement (RAP) is substantially increasing. Warm-mix recycled asphalt (WMRA) technology has made great progress, which can effectively decrease the working temperature and improve the RAP content. In this study, the rheological properties of recycled binders with incorporation of high-percentage artificial RAP binder (30-70\%) were evaluated using two types of warm-mix asphalt (WMA) additives, i.e., polyethylene wax $(\mathrm{R})$ and surfactant $(\mathrm{M})$. The dynamic shear rheometer (DSR) and beam bending rheometer (BBR) tests were conducted on the recycled binders. The results showed that the temperature and frequency played an important role in determining the complex shear modulus of the high-percentage WMRA binders. The dependency of phase angle on frequency increased after the long-term aging. The WMA additive $R$ had a relatively huge impact on the rheological properties of asphalt, which mainly occurred before the PAV aging of recycled asphalt binder; the WMA additive $M$ had no significant impact on the rheological properties of recycled asphalt binder. The WMA additive R enhanced the low-temperature rheology of recycled asphalt binder, while the WMA additive $M$ enhanced the high-temperature rheology of recycled asphalt binder. Both of these types of WMA additives improved the antifatigue performance of recycled asphalt binder. The increased content of RAP binder improved the high-temperature performance and reduced the low-temperature performance of the recycled asphalt binder. However, it had no obvious impact on the fatigue performance. In addition, there was a good linear relation between the RAP binder content and the two indexes of the multiple stress creep recovery (MSCR) test.

\section{Introduction}

The pavement recycling technology has attracted increasing attention due to its environmental sustainability and economic benefits. Some guidelines and specifications were introduced at home and abroad, making the pavement recycling technology more and more mature in engineering application [1-5]. Currently, the main asphalt pavement recycling technologies include hot central plant recycling, hot in-place recycling, cold central plant recycling, and cold in-place recycling [6]. Among them, hot central plant recycling is most widely applied. However, the mixing temperature for hot recycling in asphalt plant is generally about $170^{\circ} \mathrm{C}$. The excessive mixing temperature can cause secondary aging of the reclaimed asphalt and produce a large amount of asphalt fume and toxic gas, which will pollute the environment and cause damage to the health of construction staff. In addition, the utilization rate of RAP in the hot central plant recycling is generally between only $20 \%$ and $30 \%$.

With the development of recycling technology, the demand for higher-percentage RAP has been increasing. The National Cooperative Highway Research Program (NCHRP) report recommended to increase the content of RAP in recycled asphalt mixture and proposed that the recycled asphalt mixture can have the same uniformity and 
pavement performance as normal asphalt mixture when the content of RAP is increased through improving the design of mixture and standardizing the management and disposal of RAP [1]. Studies have shown that the content of RAP has a significant impact on the performance of recycled asphalt pavement. In particular, when the content of RAP is increased, the impact is more significant $[7,8]$. Because the increased content of RAP may cause a series of problems, such as worse low-temperature crack resistance, antifatigue performance, water damage resistance, secondary aging caused by high-temperature construction, and partial mixing in the mixing process, namely, the ineffective utilization of waste asphalt in $\operatorname{RAP}[4,9,10]$. These potential issues during the realization of recycling at large proportion pose a great challenge to pavement performance.

It is urgently needed to increase the content of RAP without reducing the pavement performance. Researchers have performed a range of related studies. Due to the existence of RAP lumps, the actual surface area of RAP is less than that of normal aggregate. Therefore, sufficient preheating can loosen RAP and increase the flow of the aged asphalt in RAP. With the increase of preheating time, the performance of reclaimed asphalt mixture is improved [11], and the content of RAP is also increased accordingly. In terms of partial mixing in the mixing process of recycled asphalt mixture and high-percentage recycled hot-mixture asphalt, Shirodkar et al. plotted a mixing curve at different degrees of mixing and observed the influence of partial mixing on the selection of new asphalt grade $[12,13]$. The utilization of recycling agent is an effective means to improve the content of RAP $[14,15]$. The recycling agent is a type of low-viscosity oil, which is characterized by low viscosity, low solubility, and high aromatic content. It is easy to spread evenly in asphalt and has good compatibility with RAP binder, which can reduce the viscosity of asphalt and supplement the missing ingredients in the aging process to soften RAP binder and restore its physical properties. Moreover, selecting appropriate recycling agent and accurately determining its content are able to improve the pavement performance of recycled asphalt mixture [16, 17].

Although those approaches mentioned above improved the content of RAP in the recycled mixture and also provided guidance for the design and construction of asphalt mixture with high percentage of RAP, higher construction temperature will inevitably generate numerous emissions in the process of mixing and construction, which will still damage the environment and consume a large amount of energy. Moreover, the secondary aging of asphalt in the mixture is inevitable due to high-temperature construction, which is less susceptible to the durability of recycled asphalt pavement. Based on the above considerations, numbers of researchers turned their attention to the WMA technology and attempted to add WMA additives into recycled asphalt mixture to reduce the construction temperature while increasing the RAP content. Thus, warm-mix recycled asphalt (WMRA) has been rapidly applied and promoted $[18,19]$.

WMRA has the following advantages: (1) it can effectively reduce the heating temperature of RAP by about $20^{\circ} \mathrm{C}$ so as to reduce the bonding of RAP in the heating barrel and improve the proportion of RAP to over $40 \%$ [20]; (2) the warm mix technology can reduce the construction temperature of recycled asphalt mixture by $20^{\circ} \mathrm{C}$ to $40^{\circ} \mathrm{C}$, prevent secondary aging of asphalt in RAP, save energy, reduce the emission of asphalt fume and toxic gases, and truly realize green transportation and resource recycling; and (3) the construction workability is improved. As the cooling rate of WMRA mixture is generally $50 \%$ of that of hot-mix recycled asphalt mixture, the compaction time of WMRA mixture can be prolonged, so that the compaction time is more sufficient and compaction is more effective [21-24]. Therefore, as an emerging technology of green transportation, WMRA has attracted increasing attention and recognition from the industry. Asphalt binder plays a key role in recycled asphalt mixture, especially for high percentage of recycling [25]. Therefore, there is an urgent need to investigate the rheological properties of high-percentage WMRA binder.

Overall, the literature review shows that the application of the WMRA techniques has a potential to enhance requirement of RAP. However, limited studies have been reported so far to characterize the aging, antideformation, and fatigue performance of WMRA binders in terms of the rheological properties. The present study was undertaken to investigate the effects of RAP binder and WMA additives on recycled binders on complex modulus and phase angle from frequency sweep, antideformation at high temperature, and fatigue behavior of WMRA binders. It is expected that the present research study would be useful in improving the understanding of the performance of WMRA binders with higher RAP contents.

The objective of this paper is to evaluate the rheological properties of recycled asphalt binders containing high percentage of artificial RAP binder (30\% to $70 \%$ ) with incorporation of two types of WMA additives. The main purposes of this paper are as follows: (1) to analyze the changing tendency of the rheological properties of recycled asphalt binder with different contents of RAP binder and (2) to analyze the influence of different types of WMA additives on the rheological properties of high percentage of WMRA binder. A series of laboratory tests were conducted, including dynamic shear rheometer (DSR) tests and beam bending rheometer (BBR) tests.

\section{Materials and Methods}

2.1. Materials. A virgin asphalt binder 90\#, commonly used in the north area of China, was selected as the base asphalt in this study to obtain the recycled asphalt binders. Considering that the RAP from milling pavement has complex sources and its own characteristics [7, 26], the 
TABle 1: Properties of 90\# asphalt and RAP binders.

\begin{tabular}{|c|c|c|c|c|c|c|c|c|}
\hline \multirow[b]{2}{*}{$\begin{array}{l}\text { Binder } \\
\text { type }\end{array}$} & \multicolumn{4}{|c|}{ Unaged } & \multirow{2}{*}{$\begin{array}{c}\text { RTFO } \\
\left(G^{*} / \sin \right)(\delta) \\
\left(58^{\circ} \mathrm{C}\right)(\mathrm{kPa})\end{array}$} & \multicolumn{3}{|c|}{ PAV } \\
\hline & $\begin{array}{c}\text { Penetration } \\
\left(25^{\circ} \mathrm{C}\right)(0.1 \mathrm{~mm})\end{array}$ & $\begin{array}{l}\text { Softening } \\
\text { point }\left({ }^{\circ} \mathrm{C}\right)\end{array}$ & $\begin{array}{c}\text { Viscosity } \\
\left(135^{\circ} \mathrm{C}\right) \\
(\mathrm{Pa} \cdot \mathrm{s})\end{array}$ & $\begin{array}{c}\left(G^{*} / \sin \right)(\delta) \\
\left(58^{\circ} \mathrm{C}\right)(\mathrm{kPa})\end{array}$ & & $\begin{array}{c}G^{*} \sin (\delta) \\
\left(25^{\circ} \mathrm{C}\right)(\mathrm{kPa})\end{array}$ & $\begin{array}{c}\text { Stiffness } \\
\left(-12^{\circ} \mathrm{C}\right)(\mathrm{MPa})\end{array}$ & $\begin{array}{l}m \text {-value } \\
\left(-12^{\circ} \mathrm{C}\right)\end{array}$ \\
\hline $90 \#$ & 84.3 & 46.0 & 0.246 & 1.9 & 3.5 & 1989 & 196 & 0.4 \\
\hline $\begin{array}{l}\text { RAP } \\
\text { binder }\end{array}$ & 37.4 & 54.1 & 0.496 & 9.0 & - & 2830 & - & - \\
\hline
\end{tabular}

artificial RAP binder was chosen in this paper in light of its more stable and controllable properties. The artificial RAP binder was obtained by subjecting the virgin binder to the rolling thin-film oven (RTFO) and long-term pressurized aging vessel (PAV) according to the AASHTO T240 and R28 for the following performance tests [27, 28]. The properties of the virgin and artificial RAP binders are shown in Table 1 . It should be noted that the $G^{*} \sin (\delta)$ $(2825 \mathrm{kPa})$ was obtained when the RAP binder was subjected to further RTFO and PAV aging.

In this study, the recycled binders without WMA additives as control binders were produced by blending the virgin asphalt with various percentages $(30 \%, 50 \%$, and $70 \%$ ) of artificial RAP binder by total weight. The virgin asphalt and RAP binder were mixed slowly according to their blending proportion using a glass bar for 10 minutes, so that the virgin and RAP binders could be mixed preliminarily. Then the mechanical stirring was utilized at $140^{\circ} \mathrm{C}$ for 15 minutes to make the two binders blend adequately. It should be noted that the blending time was not for too long so as to avoid the binders aging. For brevity, they were denoted as $30 \%-\mathrm{C}, 50 \%-\mathrm{C}$, and $70 \%-\mathrm{C}$, respectively.

Two types of WMA additives, named $\mathrm{R}$ and $\mathrm{M}$, were utilized to investigate the effect on the rheological property of the recycled binders. WMA additive $\mathrm{R}$ is a polyethylene wax which is a kind of white powder and $M$ is a kind of surfactant, which are recommended to be added into the recycled binders at a rate of $3 \%$ and $0.5 \%$ by total weight of asphalt binders, respectively. .According to the determined percentage of the two types of WMA additives, respectively, each of the WMA additive and recycled binder were blended using a glass bar slowly until there was no WMA additive on the surface of the mixed binder. Similar to the blending process of the RAP and virgin binders, the mechanical stirring was utilized at $140^{\circ} \mathrm{C}$ for 15 minutes to make binders blend adequately. The blending time should not be for too long so as to avoid the binders aging. Two types of original WMA binders containing WMA additives $\mathrm{R}$ and $\mathrm{M}$ were named R-WMA and M-WMA. According to the WMA additive used, the recycled binders containing artificial RAP binder were named RAP-R and RAP-M. Additionally, various percentages $(30 \%, 50 \%$, and $70 \%)$ of RAP-R and RAP-M were denoted as 30\%-RAP-R, 30\%-RAP-M, etc.
2.2. Frequency Sweep Test. The frequency sweep test is a primary test method to study the rheological property of asphalt binder. In this part, the complex shear modulus $\left(G^{*}\right)$ and phase angle $(\delta)$ were measured at different temperatures $\left(4^{\circ} \mathrm{C}, 16^{\circ} \mathrm{C}, 28^{\circ} \mathrm{C}, 40^{\circ} \mathrm{C}, 52^{\circ} \mathrm{C}\right.$, and $\left.64^{\circ} \mathrm{C}\right)$ in the frequency range of $0.1 \sim 50 \mathrm{~Hz}$ at each temperature. Using the timetemperature superposition principle, the results were shifted to a reference temperature of $28^{\circ} \mathrm{C}$ to conduct master curves of complex modulus and phase angle. This paper utilized the 2S2P1D model to fit the master curves describing the rheological properties of asphalt binders [29-31]. As shown in Figure 1, the 2S2P1D model consists of two springs, two parabolic creep elements, and one dashpot with 7 parameters, which can be determined using the following formulation:

$$
G^{*}(i \omega)=G_{e}+\frac{G_{g}-G_{e}}{1+\alpha\left(i \omega t \tau_{0}\right)^{-k}+\left(i \omega \tau_{0}\right)^{-h}+\left(i \omega \beta \tau_{0}\right)^{-1}},
$$

where $G_{e}$ is the static modulus. When the material is rheological solid, $G_{e}>0$, and when the material is rheological fluid, $G_{e}=0$. In this paper, $G_{e}$ is $0 . G_{g}$ is the glassy modulus $\left(G_{g}=10^{9} \mathrm{~Pa}\right) . \alpha, k, h, \beta$, and $\tau_{0}$ are parameters of this model and $0<k<h<1$. Meanwhile, $\beta$ is constant and defined by

$$
\eta=\left(G_{g}-G_{e}\right) \beta \tau_{0}
$$

where $\eta$ is the Newtonian viscosity.

Complex shear modulus $G^{*}$ consists of two parts, which are the energy storage shear modulus $G^{\prime}$ and loss shear modulus $G^{\prime \prime}$. Besides, $G^{*}$ can be separated as follows [32]:

$$
G^{*}=G^{\prime}+i G^{\prime \prime}
$$

Therefore, on the basis of the (3), the 2S2P1D model can be separated and rewritten as follows:

$$
\begin{aligned}
G^{*}(\omega) & =\frac{G_{g}}{1+A(\omega)+i B(\omega)} \\
& =\frac{G_{g} \times(1+A(\omega)-i B(\omega))}{(1+A(\omega))^{2}+B^{2}(\omega)} \\
& =\left[\frac{G_{g} \times(1+A(\omega))}{(1+A(\omega))^{2}+B^{2}(\omega)}\right]+i\left[\frac{G_{g} \times(-B(\omega))}{(1+A(\omega))^{2}+B^{2}(\omega)}\right],
\end{aligned}
$$




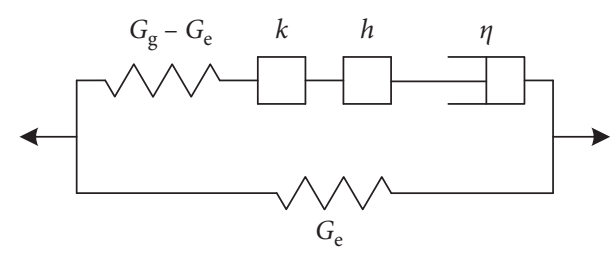

FIgURE 1: 2S2P1D model.

where

$$
\begin{aligned}
A(\omega)= & \alpha(\omega \tau)^{-k} \times \cos \left(\frac{k \pi}{2}\right)+(\omega \tau)^{-h} \times \cos \left(\frac{h \pi}{2}\right), \\
B(\omega)= & -(\omega \beta \tau)^{-1}-\alpha(\omega \tau)^{-k} \times \sin \left(\frac{k \pi}{2}\right)-(\omega \tau)^{-h} \\
& \times \sin \left(\frac{h \pi}{2}\right) .
\end{aligned}
$$

Then, the master curves of complex modulus and phase angle can be obtained according to (3) and (4). Besides, the objective error function is defined as

$$
f_{2}=\frac{1}{M} \sqrt{\sum_{j=1}^{M}\left(1-\frac{G_{c, j}^{\prime}}{G_{m, j}^{\prime}}\right)^{2}}+\frac{1}{M} \sqrt{\sum_{j=1}^{M}\left(1-\frac{G_{c, j}^{\prime \prime}}{G_{m, j}^{\prime \prime}}\right)^{2}},
$$

where $G_{c, j}^{\prime}$ and $G_{c, j}^{\prime \prime}$ are the predicted energy storage shear modulus and loss shear modulus, respectively, and $G_{m, j}^{\prime}$ and $G_{m, j}^{\prime \prime}$ are the actual values, correspondingly.

2.3. BBR Low-Temperature Rheological Property. The rheological property of asphalt binder is the most significant factor for the low-temperature cracking of asphalt pavement [33]. Thus, this paper utilized the CAM model to fit the master curves and Burgers' model to analyze the viscoelasticity of recycled binders. The reference temperature was $-12^{\circ} \mathrm{C}$.

The CAM model is defined as

$$
S(t)=S_{\text {glass }}\left[1+\left(\frac{t}{\lambda}\right)^{\beta}\right]^{(-\kappa / \beta)},
$$

where $S_{\text {glass }}=3 \times 10^{3} \mathrm{MPa}$ is constant and $\lambda, \beta$, and $\kappa$ are the parameters of this model.

The objective error function is defined as

$$
f_{1}=\frac{1}{M} \sqrt{\sum_{j=1}^{M}\left(1-\frac{D_{c, j}}{D_{m, j}}\right)^{2}},
$$

where $D_{c, j}$ is the model predictive value of creep compliance; $D_{m, j}$ is the actual value of creep compliance; and $M$ is the number of data points.

The asphalt binder is subjected to the flexural deflection as the BBR test time goes on; the bending tendency is depicted in Figure 2.

As per the deflection of the binder, the Burgers model was employed to evaluate the viscoelastic property through

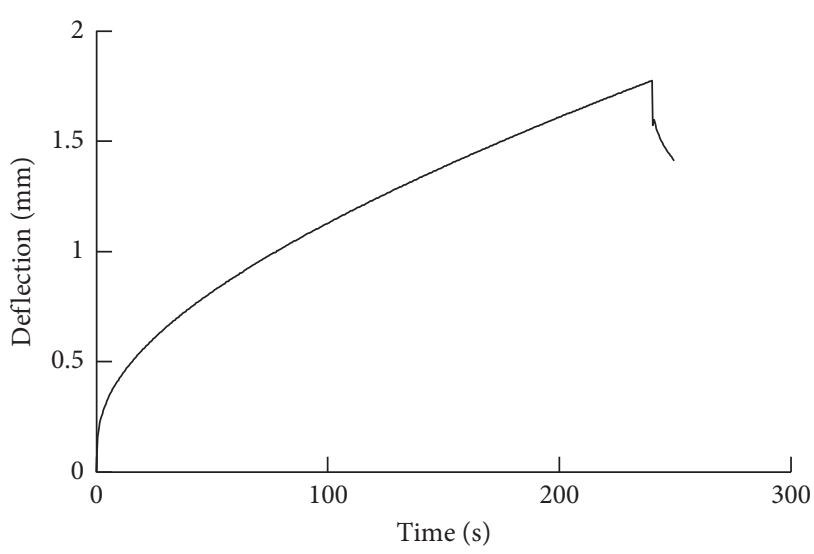

FIGURE 2: Loading time-deflection figure of BBR asphalt beam.

the analysis of its parameters. The Burgers model is composed of one Maxwell's model and one Kelvin's model including four components in series $[34,35]$, as shown in Figure 3 .

The creep compliance is determined by the following equation:

$$
D(t)=\frac{1}{E_{1}}\left(1-e^{\left(-\left(E_{1} / \eta_{1}\right) t\right)}\right)+\frac{1}{E_{2}}+\frac{t}{\eta_{2}},
$$

where $E_{1}$ and $\eta_{1}$ are the delayed elastic modulus and viscous parameter of the Kelvin model and $E_{2}$ and $\eta_{2}$ are the instantaneous elastic modulus and viscosity coefficient of the Maxwell model.

In this study, the BBR tests were conducted at 4 temperatures $\left(-6,-12,-15\right.$, and $\left.-18^{\circ} \mathrm{C}\right)$ in accordance with AASHTO T313 [36] using the recycled asphalt binders subjected to long-term aging.

2.4. Multiple Stress Creep Recovery (MSCR) Tests. The MSCR test according to AASHTO TP70 [37] is conducted on the binders to evaluate the high-temperature performance of rutting resistance on the basis of the creep characteristic of binders [21, 38, 39]. All the binders were short-term aged using RTFO test. Two creep stress levels, $0.1 \mathrm{kPa}$ and $3.2 \mathrm{kPa}$, were adopted in this test involving 10 consecutive cycles, and each cycle consists of a creep loading period (1s) and a recovered period $(9 \mathrm{~s})$. The nonrecoverable creep compliance $\left(J_{n r}\right)$ and percent recovery $(R)$ can be determined using the following formulations:

$$
\begin{gathered}
J_{n r}=\frac{\gamma_{n r}}{\tau}, \\
R=\frac{\gamma_{P}-\gamma_{n r}}{\gamma_{P}-\gamma_{0}},
\end{gathered}
$$

where $\gamma_{p}, \gamma_{n r}$, and $\gamma_{0}$ are the peak strain, the residual strain, and the initial strain in each cycle, respectively, and $\tau$ is the shear stress. So, $\gamma_{p}$ is the strain recorded at the end of $1 \mathrm{~s}, \gamma_{n r}$ is the strain recorded at recorded at the end of the $10 \mathrm{~s}$ creep phase, which is the unrecoverable strain, and $\gamma_{0}$ is the strain at the beginning of $1 \mathrm{~s}$. Thus, equation (10) is the expression of the nonrecoverable creep compliance $\left(J_{n r}\right) .\left(\gamma_{P}-\gamma_{0}\right)$ 


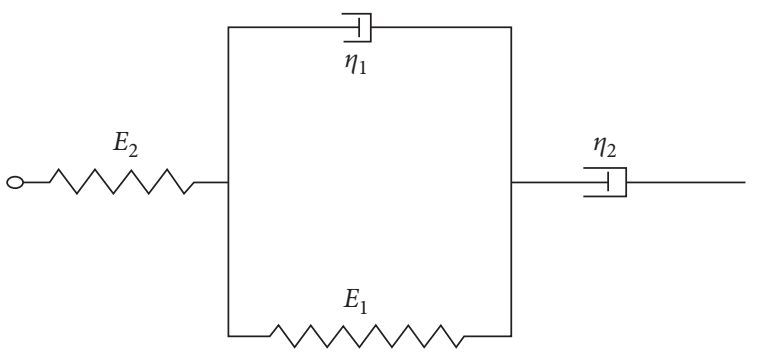

Figure 3: Burgers' model.

represents the total strain recorded during the loading period, while $\left(\gamma_{P}-\gamma_{n r}\right)$ represents the recoverable strain during the recovered period. Thus, equation (11) is the expression of percent recovery (R).

In this study, the MSCR test was performed at four temperatures, $46^{\circ} \mathrm{C}, 52^{\circ} \mathrm{C}, 58^{\circ} \mathrm{C}$, and $64^{\circ} \mathrm{C}$.

2.5. Linear Amplitude Sweep (LAS). Linear amplitude sweep (LAS) test, that is, asphalt accelerated fatigue test, is the main test method used to evaluate the fatigue performance of asphalt in the specifications of AASHTO [40]. In this test, the strain-controlled loading method was adopted. The amplitude of loaded sine wave increased linearly from $0.1 \%$ to $30 \%$, and the sweep time was $300 \mathrm{~s}$.

In the LAS test, elastic deformation and plastic deformation will occur to asphalt in turn under repeated loading. When the load is applied to a certain phase, the strain of the material continues to increase and the stress decreases, indicating yield of the material. When the material yields, the normal stress is the yield stress of the material. At this time, the corresponding strain is the yield strain. The larger the yield stress, the stronger the resistance to deformation under a certain load. The larger the yield strain, the greater the deformation under maximum load, and the better the elasticity of the asphalt material. And studies show that there is also a peak of phase angle in the LAS test. If the peak of shear stress is taken as the yield stress of the material, the final failure of the material can be used to analyze by the peak of phase angle, because the peak of phase angle always lags behind the yield stress [41]. In this paper, the peak of shear stress is taken as the yield stress, and the corresponding strain is the yield strain.

The LAS test is an accelerated procedure to assess the fatigue resistance of asphalt binders according to AASHTO TP 101-14 [42]. As we all know, the traditional straincontrolled fatigue equation is defined as

$$
N_{f}=A\left(\gamma_{\max }\right)^{-B}
$$

where $\gamma_{\max }$ is the amplitude of the applied shear strain; $A$ is the fatigue law coefficient obtained from the following equation: $A=\left(f \times\left(D_{f}\right)^{\left[1+\left(1-C_{2}\right) \alpha\right]} /\left\{\left[1+\left(1-C_{2}\right) \alpha\right] \times\left(\pi C_{1}\right.\right.\right.$ $\left.\left.\left.C_{2}\right)^{\alpha}\right\}\right) ; B=2 \alpha$.The two coefficients can be determined from the LAS test.
The LAS test contains two main steps. In the first step, a frequency sweep, whose frequency is varied from 0.2 to $30 \mathrm{~Hz}$ at a constant shear strain amplitude of $0.1 \%$ within the LVE range, is performed to determine the damage analysis " $\alpha$ " parameter. " $\alpha$ " is obtained by the following equations:

$$
\begin{aligned}
\log G^{\prime}(\omega) & =m(\log \omega)+b, \\
G^{\prime}(\omega) & =G^{*}(\omega) \times \cos \delta(\omega),
\end{aligned}
$$

$$
\alpha=\frac{1}{m}
$$

In the second step, an amplitude sweep is carried out to identify the damage accumulation of the binders over a range of amplitude levels linearly from 0 to $30 \%$ at a constant frequency level of $10 \mathrm{~Hz}$ in $5 \mathrm{~min}$. The viscoelastic continuum damage (VECD) model is introduced to determine the fatigue life of the binders [43-46]. By means of the VECD theory, the fatigue behavior under varying strain levels of binders can be predicted [47].

The damage accumulation $D$ with testing time can be obtained as follows:

$$
D(t) \cong \sum_{i=1}^{N}\left[\pi \gamma_{0}^{2}\left(C_{i-1}-C_{i}\right)\right]^{(\alpha /(1+\alpha))}\left(t_{i}-t_{i-1}\right)^{(1 /(1+\alpha))}
$$

where $C(t)=\left(G^{*}(t) / G^{*}\right)$ (Initial) is the material integrity parameter. The power law model has been introduced for analytically relating the material integrity $C$ to the damage intensity $S$ as follows $[43,48]$ :

$$
C(t)=C_{0}-C_{1} \times D^{C_{2}},
$$

where $C_{0}=1$ is the initial value of $C$, and $C_{1}$ and $C_{2}$ are curve fitting parameters.

According to Singh's research [47], the maximum peak shear stress is introduced to define the failure point as follows:

$$
D_{f}=\left(\frac{C_{0}-C_{\text {Peakstress }}}{C_{1}}\right)^{\left(1 / C_{2}\right)} .
$$

The calculation formula for fatigue life is

$$
N_{f}=A\left(\gamma_{\max }\right)^{-B} \text {, }
$$

where $\gamma_{\max }$ is the expected maximum strain level (\%); $A$ and $B$ are the fatigue correlation coefficients; $A=(f \times$ $\left.\left(D_{f}\right)^{\left[1+\left(1-C_{2}\right) \alpha\right]} /\left\{\left[1+\left(1-C_{2}\right) \alpha\right] \times\left(\pi C_{1} C_{2}\right)^{\alpha}\right\}\right) ; B=2 \alpha$; and $f$ is the loading frequency.

In this study, the LAS test was conducted at $20^{\circ} \mathrm{C}$ using the long-term asphalt binders.

\section{Results and Discussion}

3.1. Frequency Sweep Analysis. To assess the availability of 2S2P1D model fitting the master curves, Figure 4 illustrates the master curves of complex shear modulus and phase angles of the three types of virgin asphalt binders, in which the reference temperature is $28^{\circ} \mathrm{C}$. 


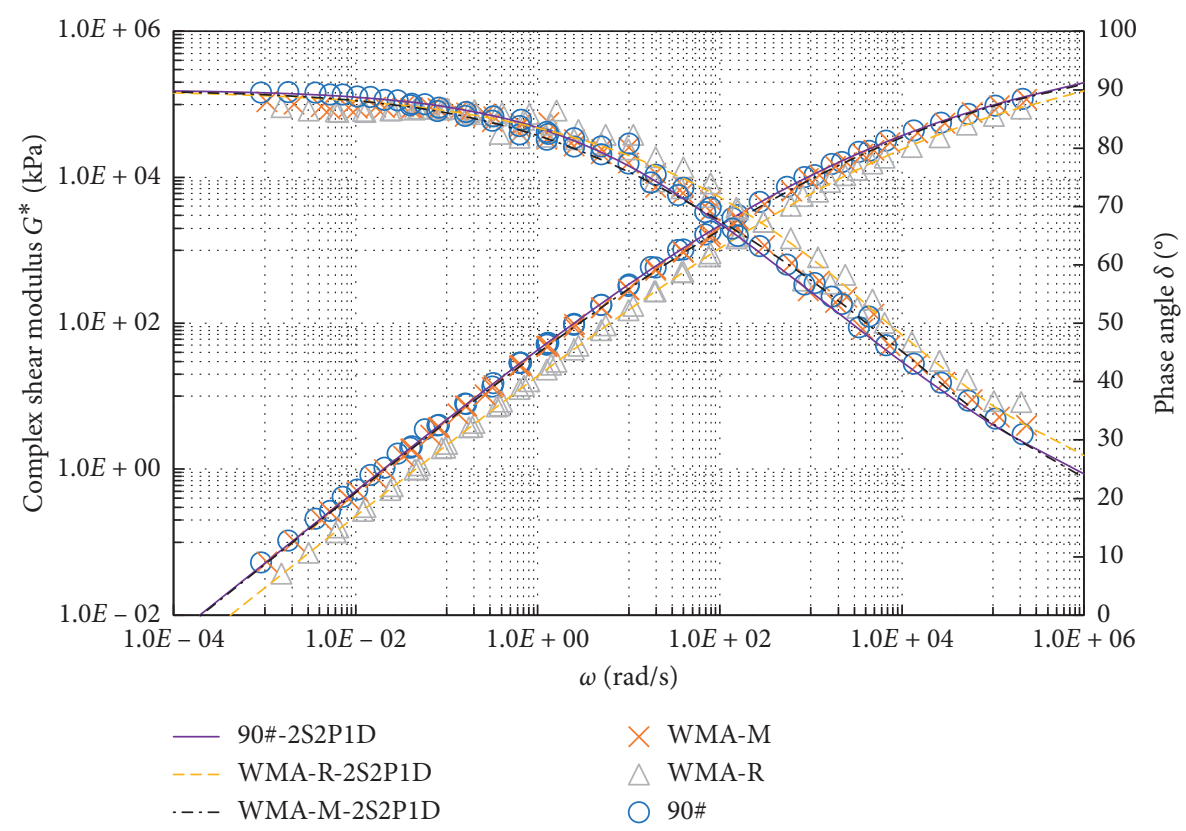

FIgURE 4: Complex shear modulus and phase angle master curves of three types of virgin asphalt binders.

It can be observed that the 2S2P1D model is available for the WMA binders in this paper. With respect to the effect of WMA additives on the rheological property of binders, Figure 4 displays that the incorporation of WMA additive $\mathrm{R}$ causes lower complex shear modulus and higher phase angle.

It can be seen from Figure 4, there is no noticeable difference between the WMA-M binder and 90\# base asphalt in terms of complex shear modulus and phase angle, and the master curves fitted by the 2S2P1D model for the two binders almost coincide with each other. It indicates that the addition of WMA additive $M$ has no remarkable impact on the viscoelasticity of asphalt. The complex shear modulus of WMA-R binder is less than that of the other two binders; nevertheless, there is no big difference in the phase angle in the low frequency region. As the frequency increases, the phase angle of WMA-R binder is slightly larger than that of WMA-M binder and 90\# base asphalt.

The result reveals that the addition of WMA additive $\mathrm{R}$ decreases the complex shear modulus of asphalt, increases the phase angle, and slightly reduces antideformation property. However, the addition of WMA additive $M$ with the recommended dosage had little impact on the rheological properties of asphalt. It may be because the WMA additive $M$ is a type of surfactant, which is mainly used as a bridge to build a better connection between the asphalt and aggregate, so that the asphalt and aggregate can be coated completely at a lower temperature. Thus, the WMA additive $M$ mainly has an effect on the asphalt mixture, while the viscosity of asphalt binder has no remarkable reduction, while the WMA additive $\mathrm{R}$ is a type of organic agent, which can reduce the viscosity of asphalt binders significantly, so that the rheological properties of recycled asphalt binders change a lot comparing to those of control and RAP-M binders. Besides, due to the mechanism of the two WMA additives, it is possible to utilize more RAP in recycled asphalt mixture at a lower temperature with a well coating condition.

In this paper, three types of recycled asphalt binders with $30 \%, 50 \%$, and $70 \%$ of RAP binder were selected to analyze the master curves of complex shear modulus and phase angle of the asphalt binders before and after PAV aging.

The master curves of the complex shear modulus and phase angle of the control binder before and after PAV aging are shown in Figures 5-7. It can be seen that the master curves of the complex shear modulus before and after aging fit well with 2S2P1D model. As the content of RAP binder increases, master curves of complex shear modulus exhibit significant change. After PAV aging, the complex shear modulus improved significantly in the low frequency region compared to that prior to aging. However, it does not change significantly in the high frequency region. It indicates that PAV aging has a relatively greater impact when the load frequency is relatively lower. It can be seen by the comparison that the fitting precision of the phase angle master curve after PAV aging is obviously worse than that before aging, indicating that the viscoelasticity of recycled binder becomes more complex under the load frequency after aging. There is no big difference in the phase angle in highand low-frequency regions; an obvious difference is shown in the intermediate frequency region. It indicates that the control binder exhibits stronger elasticity at $0.01-10^{4} \mathrm{rad} / \mathrm{s}$ after aging.

The master curves of complex shear modulus and phase angle of RAP-M binder before and after PAV aging are shown in Figures 8-10 above. It can be seen that the trend is approximately similar to that of the master curve of the control binder. It indicates that the addition of $\mathrm{M}$ has little impact on the rheological properties of recycled binder.

The master curves of the complex shear modulus and phase angle of RAP-R binder before and after PAV aging 


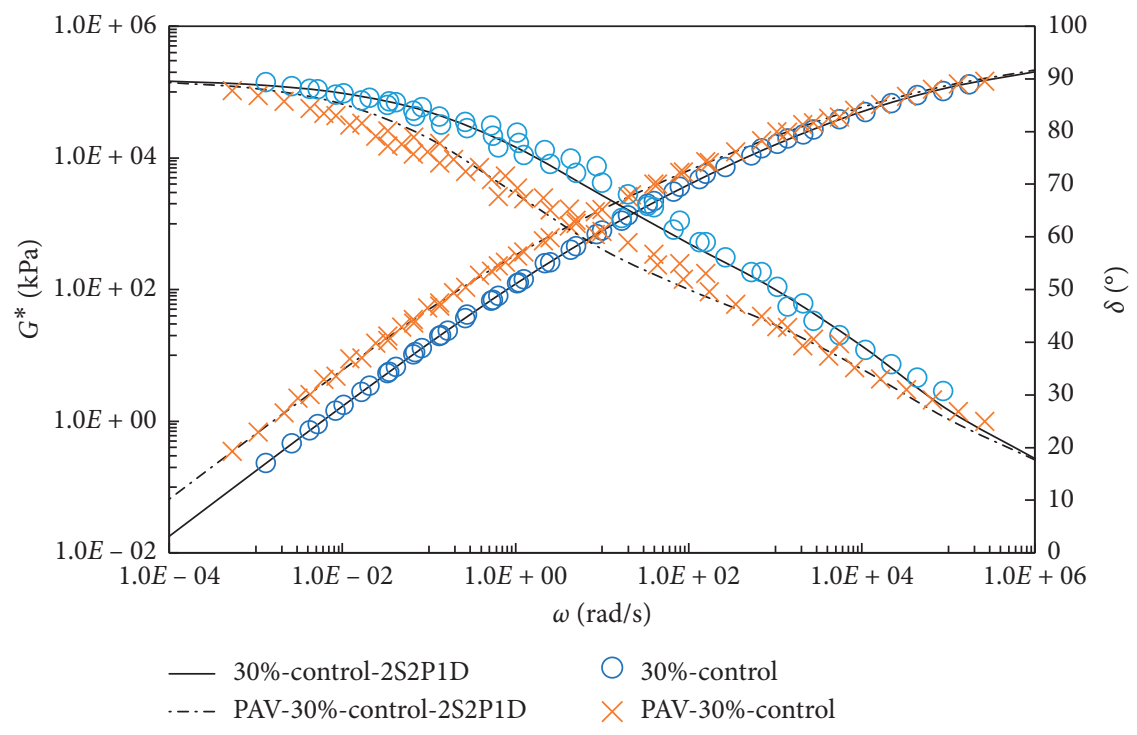

Figure 5: Complex shear modulus and phase angles master curves for control binder containing 30\% RAP binder before and after PAV aging.

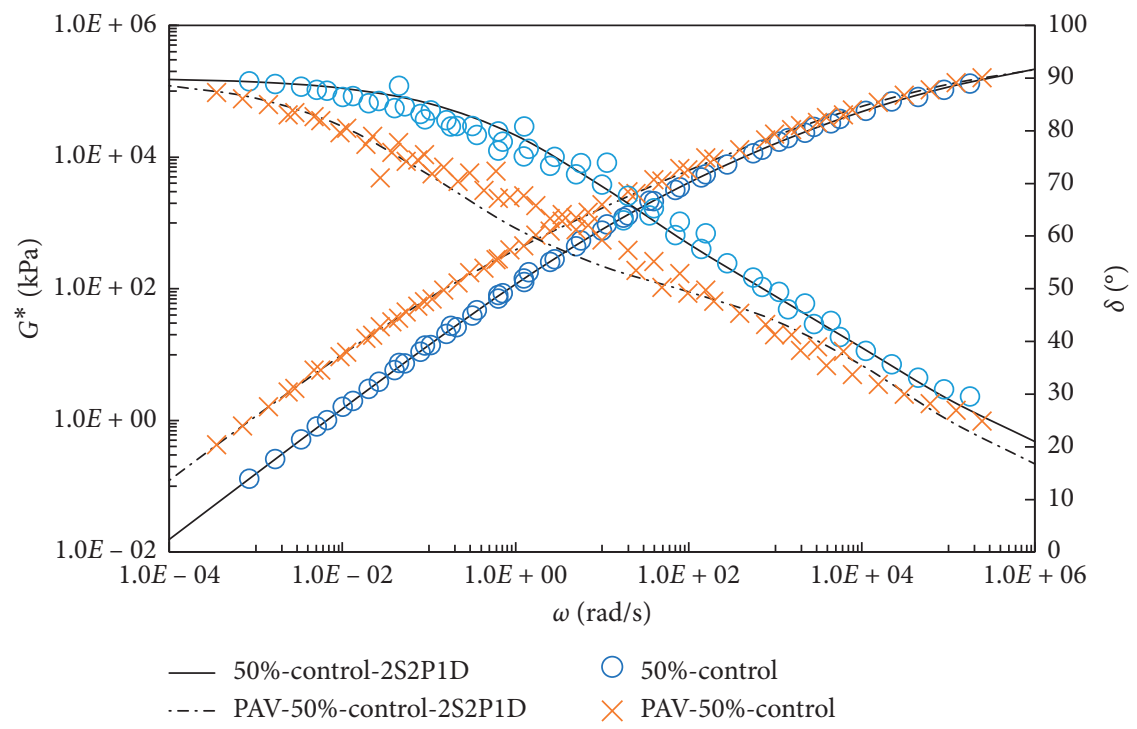

FIGURE 6: Complex shear modulus and phase angles master curves for control binder containing 50\% RAP binder before and after PAV aging.

are shown in Figures 11-13. The complex shear modulus shows a trend similar to that of the control binders. Due to the addition of $R$, the phase angle changes greatly. In particular, when the RAP binder content is $50 \%$ and $70 \%$, the phase angle of RAP-R binder tends to decrease at low frequency prior to PAV aging, which is even less than that after aging. There is a relatively distinct deviation error in the fitting curve of the 2S2P1D model. This may be explained by the fact that comparing the control and RAP-
$\mathrm{M}$ binders, the viscosity of RAP-R binder was reduced significantly with the addition of WMA additive $R$. As the temperature went up, that is, corresponding to the medium and low frequency, the reduced viscosity caused the change of rheological property of RAP-R binder. Furthermore, the phase angle represents the viscosity and elasticity of asphalt. When the RAP binder content increases, the viscoelasticity of RAP-R binder may present a nonlinear change. Thus, the master curves of phase angle are not ideal 


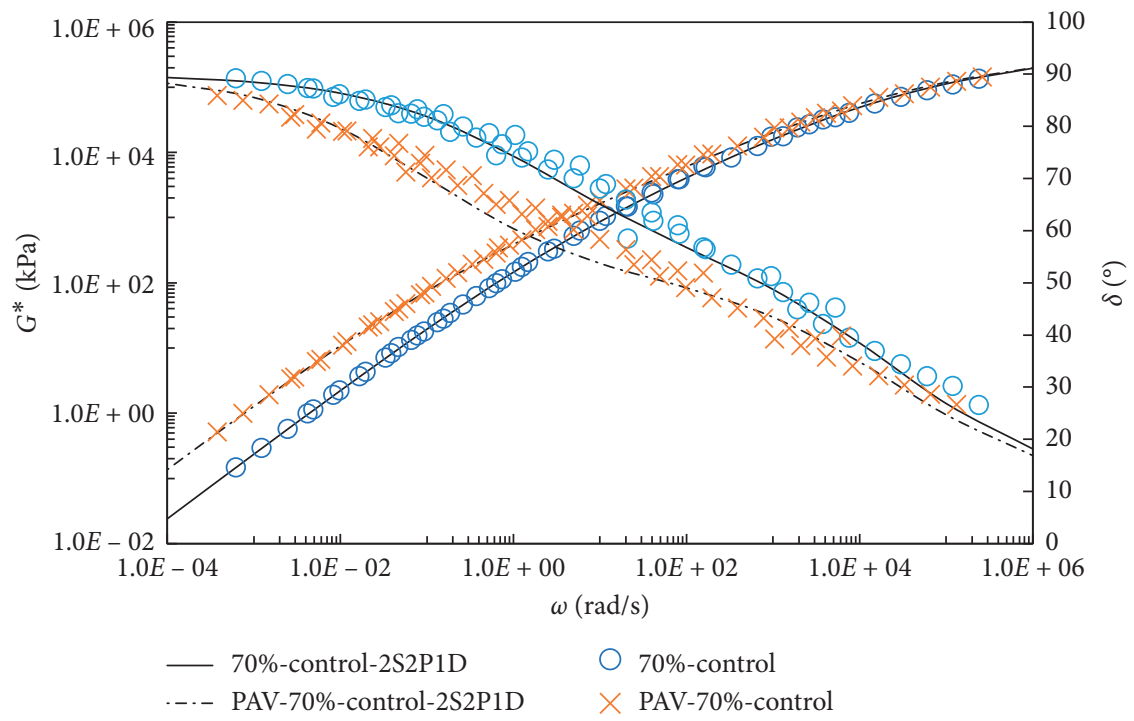

FIGURE 7: Complex shear modulus and phase angles master curves for control binder containing 70\% RAP binder before and after PAV aging.

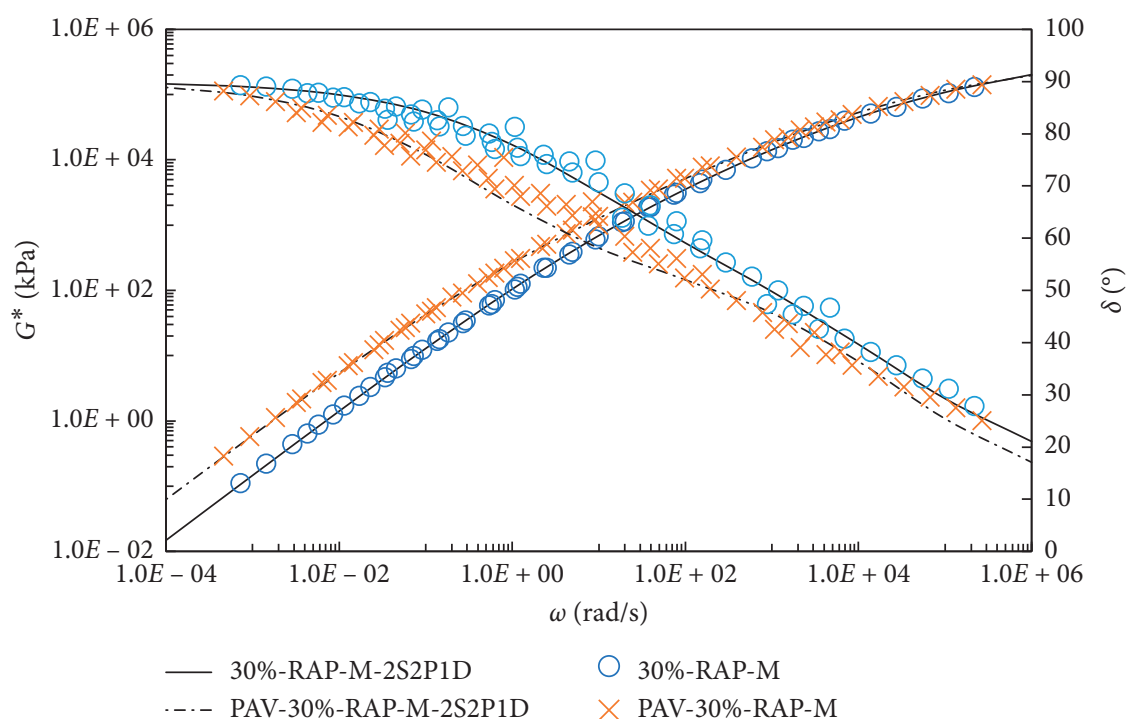

Figure 8: Complex shear modulus and phase angles master curves for RAP-M binder containing 30\% RAP binder before and after PAV aging.

in the low and medium frequency regions using the 2S2P1D model.

But after PAV aging, the viscoelasticity of RAP-R binder tends to be normal. Therefore, the influence of $R$ on the viscoelasticity of the recycled asphalt occurs before PAV aging.

3.2. Analysis of Low-Temperature Rheology in the BBR Test. The three types of recycled binders with $30 \%, 50 \%$, and $70 \%$ of RAP binder after PAV aging are chosen to analyze the low-temperature rheological properties of recycled asphalt binder. The master curves are plotted as shown in Figures 14(a)-14(c).
It can be seen from Figure 14 that the master curves of creep compliance of the three types of recycled asphalt binder are below the 90\# base asphalt curve. It indicates that, due to the addition of RAP binder, the recycled asphalt binder is harder than the 90\# base asphalt at low temperature, and the creep performance is reduced. Therefore, the ability to resist crack at low temperature is poor. However, with the increase of the content of RAP binder, the creep compliance curves have no remarkable change; thus, the RAP binder contents have little effect on the rheological properties at low temperature in this research.

It can be seen by the comparison that the addition of $R$ obviously improved the low-temperature creep performance 


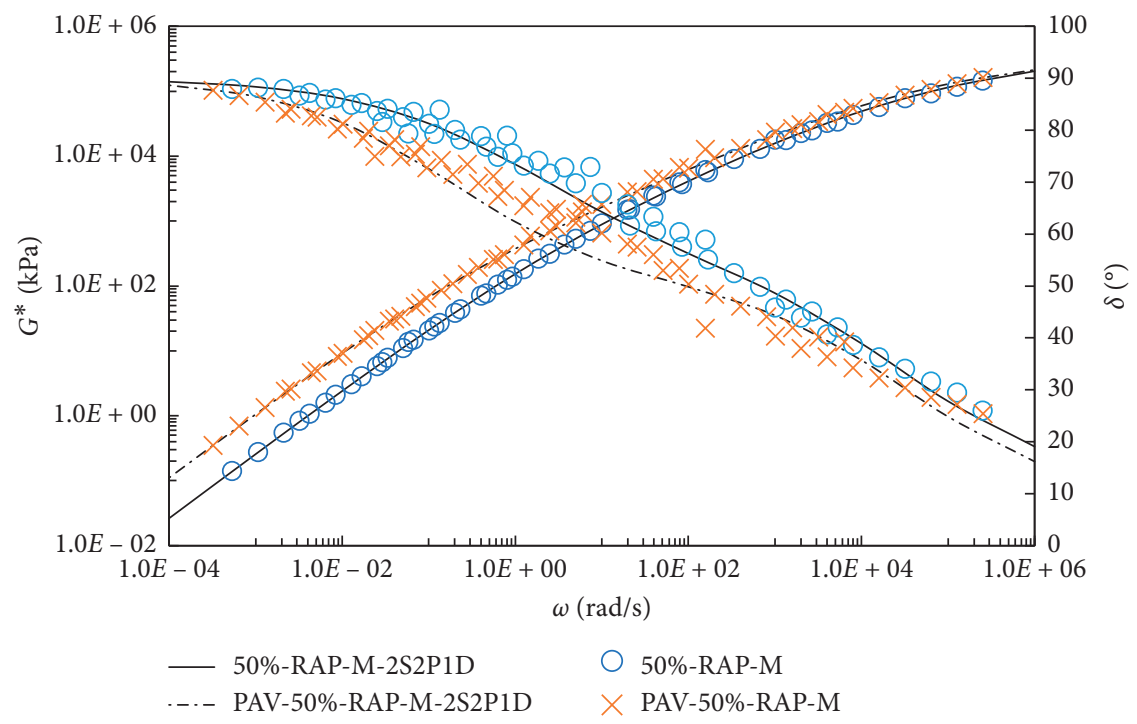

FIGURE 9: Complex shear modulus and phase angles master curves for RAP-M binder containing 50\% RAP binder before and after PAV aging.

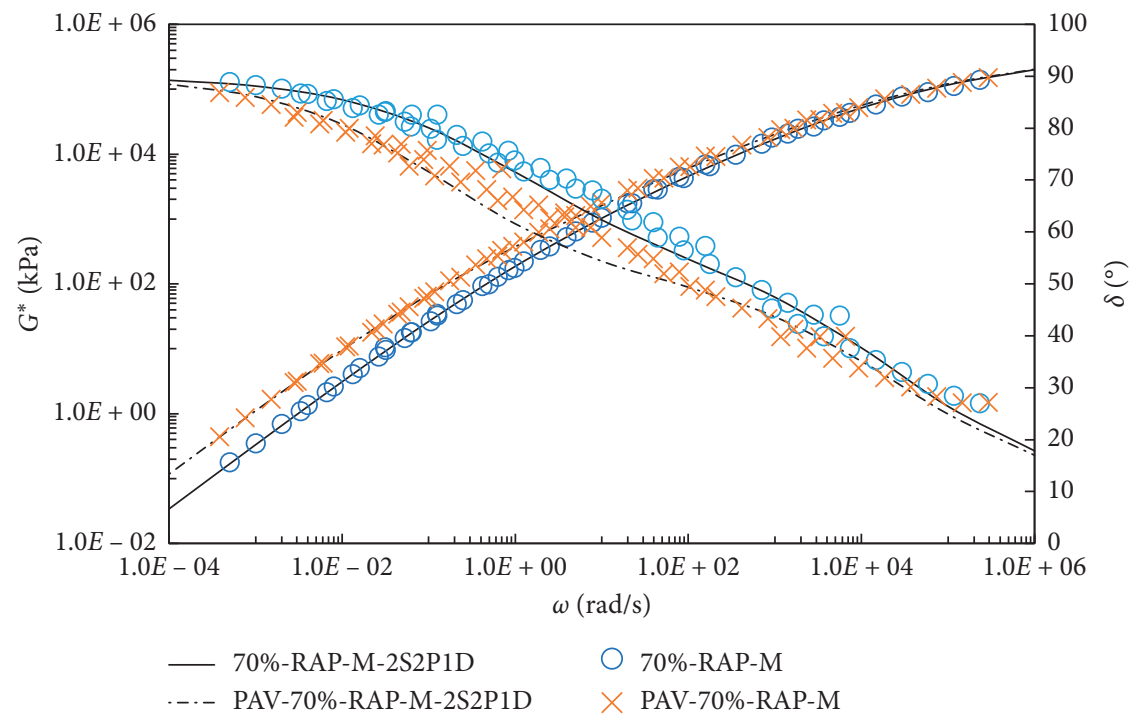

FIGURE 10: Complex shear modulus and phase angles master curves for RAP-M binder containing 70\% RAP binder before and after PAV aging.

of the recycled binder. When the RAP binder content is $30 \%$, it reaches the same level as $90 \#$ base asphalt, while the difference between $50 \%-\mathrm{R}$ binder or $70 \%-\mathrm{R}$ binder and $90 \#$ base asphalt is also obviously less than the other two types of recycled asphalt. In general, the low-temperature creep performance of the three binders is ranked as follows: RAP$\mathrm{R}$ binder $>\mathrm{RAP}-\mathrm{M}$ binder $>$ control binder.

Creep compliance at different temperatures was fitted to obtain the four viscoelastic parameters of the Burgers model. At the same time, the corresponding delay time $\tau=\left(\tau_{1} / E_{1}\right)$ and relaxation time $\lambda=\left(\lambda_{2} / E_{2}\right)$ can be calculated. The results at different temperatures are shown in Figures 15(a)15(d).

It can be observed from Figure 15 that the Burgers model parameters of the three types of recycled binders increase as the temperature decreases. The lower the temperature, the greater the variation. In Figure 15(a), at the same temperature, the elastic modulus of RAP-R is the smallest, while that of the control binder is the largest. It indicates that the control binder is the hardest and RAP-R is the softest. $E_{2}$ represents the instantaneous elastic modulus. At the same temperature, RAP-R binder has the smallest $E_{2}$, while $E_{2}$ of 


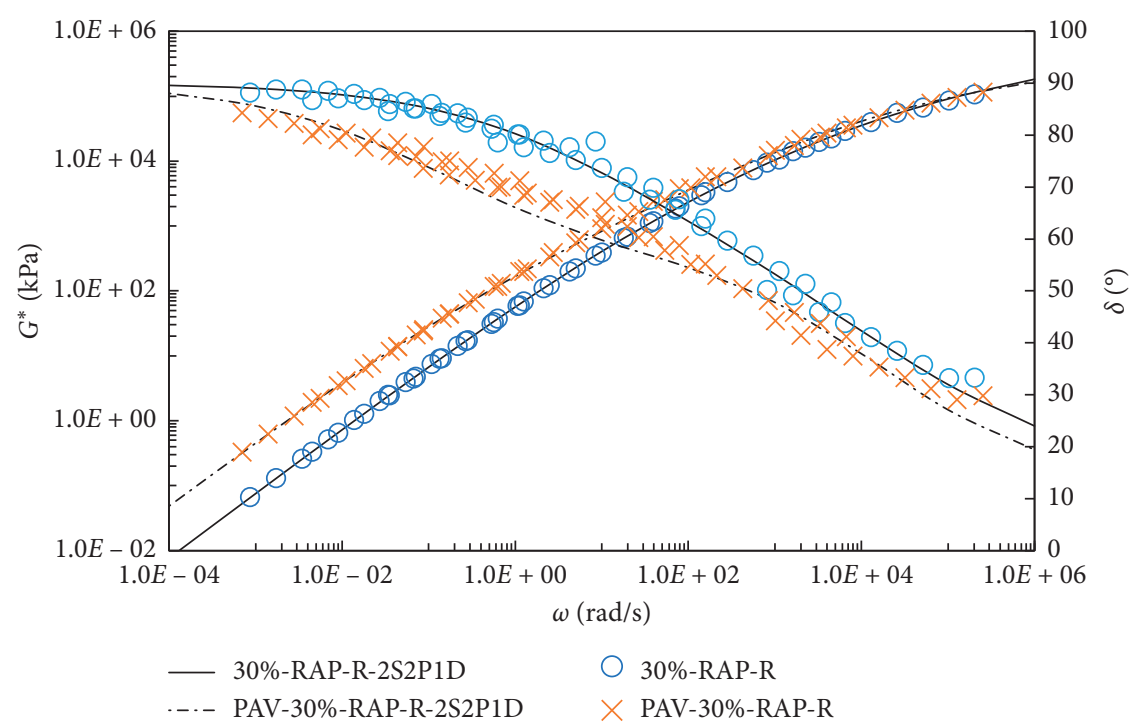

FIgURe 11: Complex shear modulus and phase angles master curves for RAP-R binder containing 30\% RAP binder before and after PAV aging.

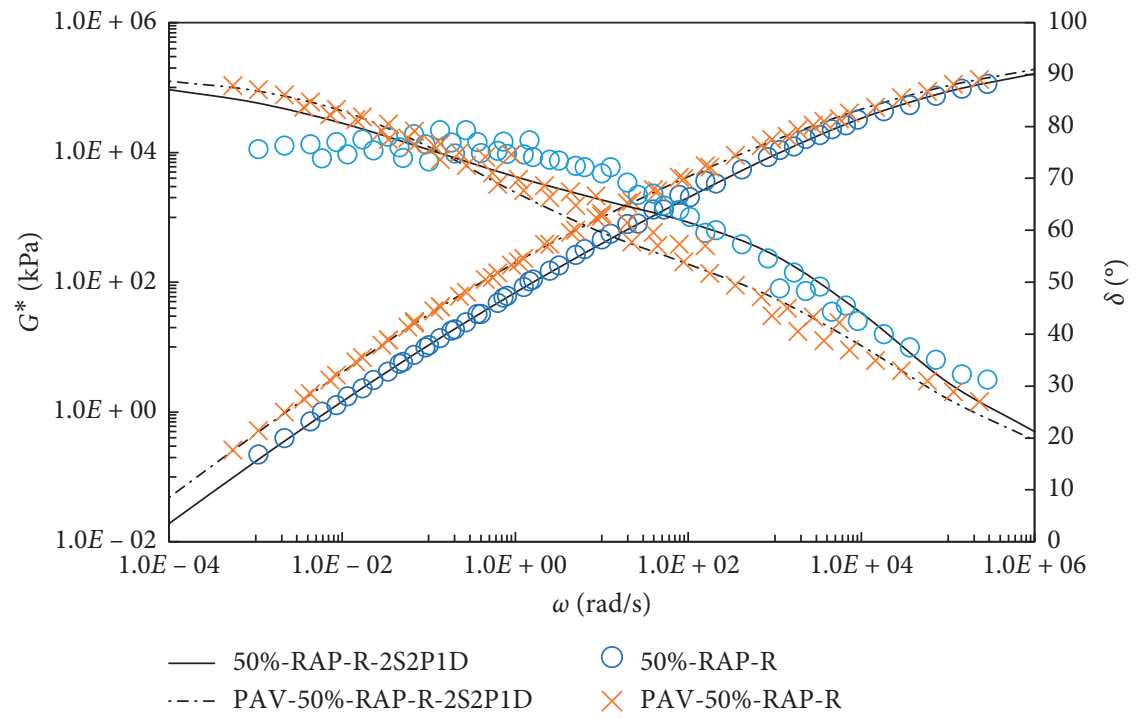

Figure 12: Complex shear modulus and phase angles master curves for RAP-R binder containing 50\% RAP binder before and after PAV aging.

RAP-M binder and control binder is almost the same. $\eta_{2}$ represents the viscosity coefficient of unrecoverable deformation. When the temperature decreases, $\eta_{2}$ increases, indicating the reduction of the viscous component of asphalt; at the same temperature, RAP-R binder has the smallest $\eta_{2}$, which indicates that it has the highest viscosity and the lowtemperature crack resistance is better than that of the other two recycled binders. Besides, with the increase of the RAP binder content, $\eta_{2}$ increases gradually, which shows that the RAP binder content will reduce the low-temperature performance of the recycled binder.
The calculation results of the relaxation time $\lambda$ are shown in Figure 16. The relaxation time $\lambda$ represents that the stress dissipates over time. The longer the relaxation time, the lower the relaxation rate and the slower the dissipation of stress. Figure 16 depicts that with the decrease of temperature, the relaxation time is prolonged. There is a good linear relation between $\lambda$ and temperature, and the linear regression equations and correlation coefficients are shown in Table 2 . The addition of $R$ significantly reduces the relaxation time of recycled asphalt binder. The relaxation time of RAP$\mathrm{M}$ binder is also less than that of the control binder. 


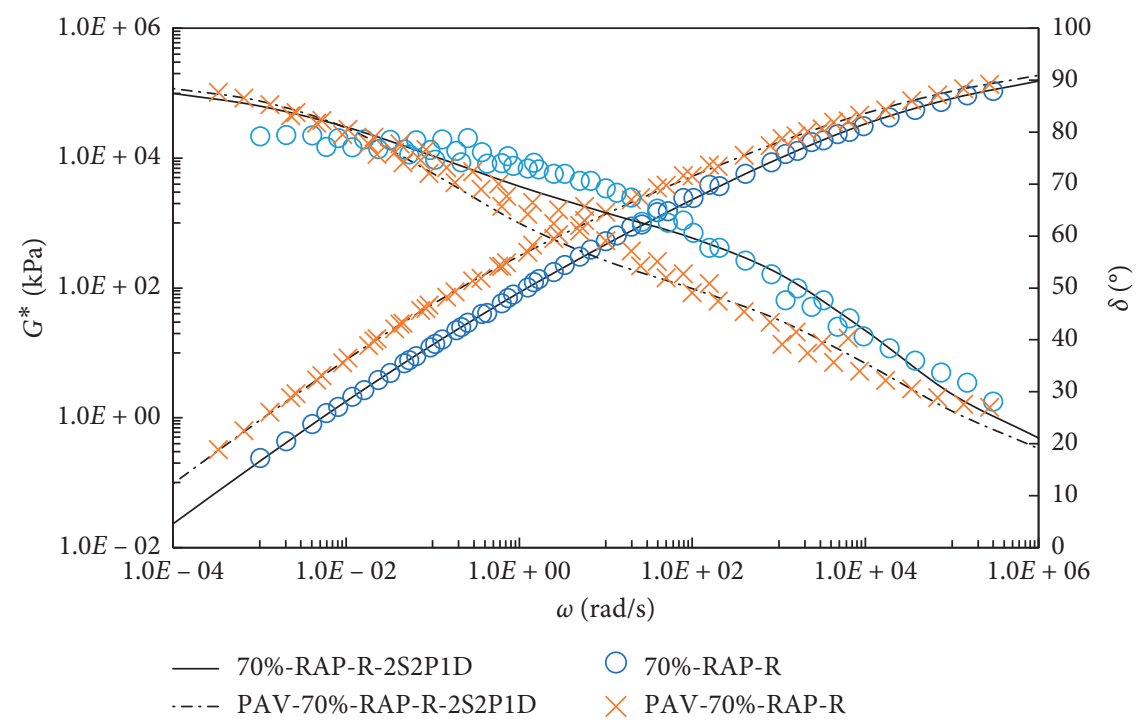

FIgURe 13: Complex shear modulus and phase angles master curves for RAP-R binder containing 70\% RAP binder before and after PAV aging.

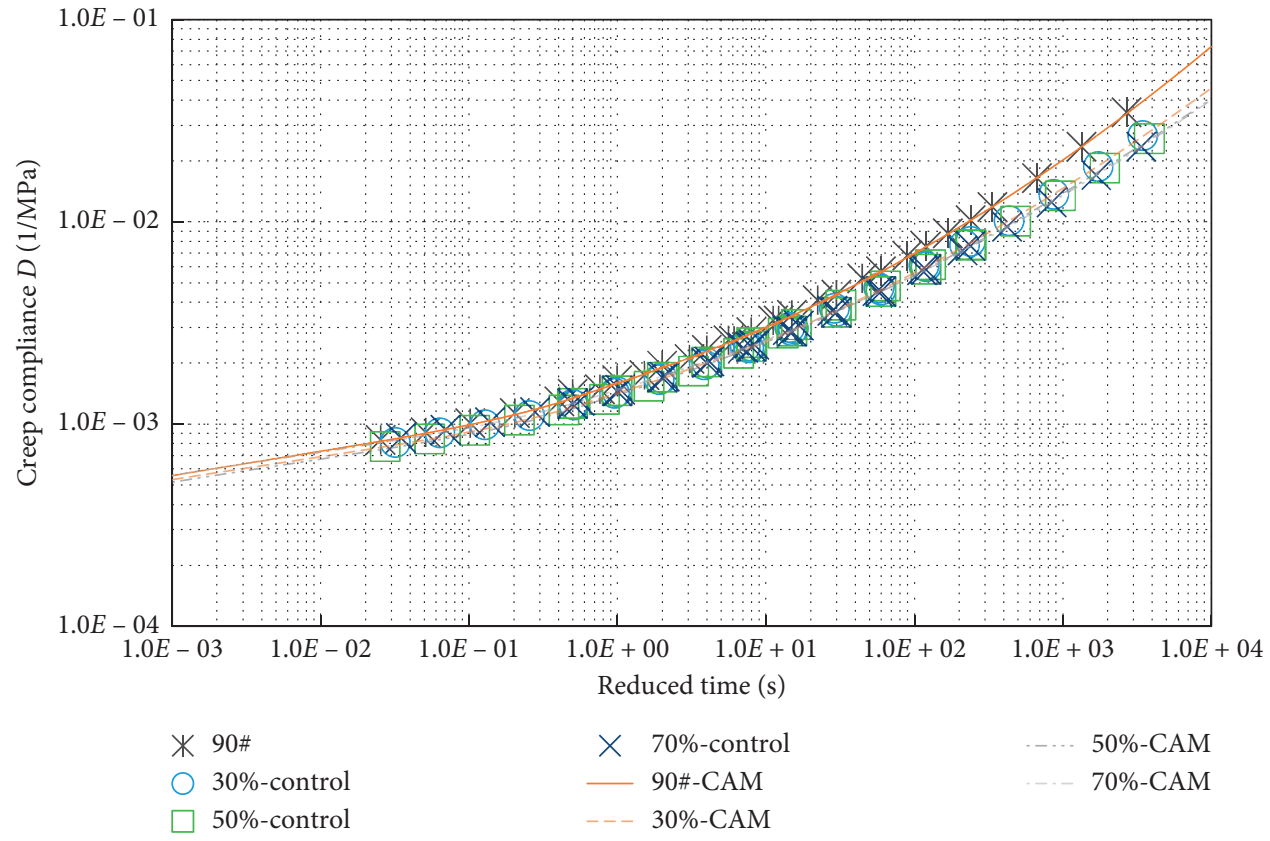

(a) 


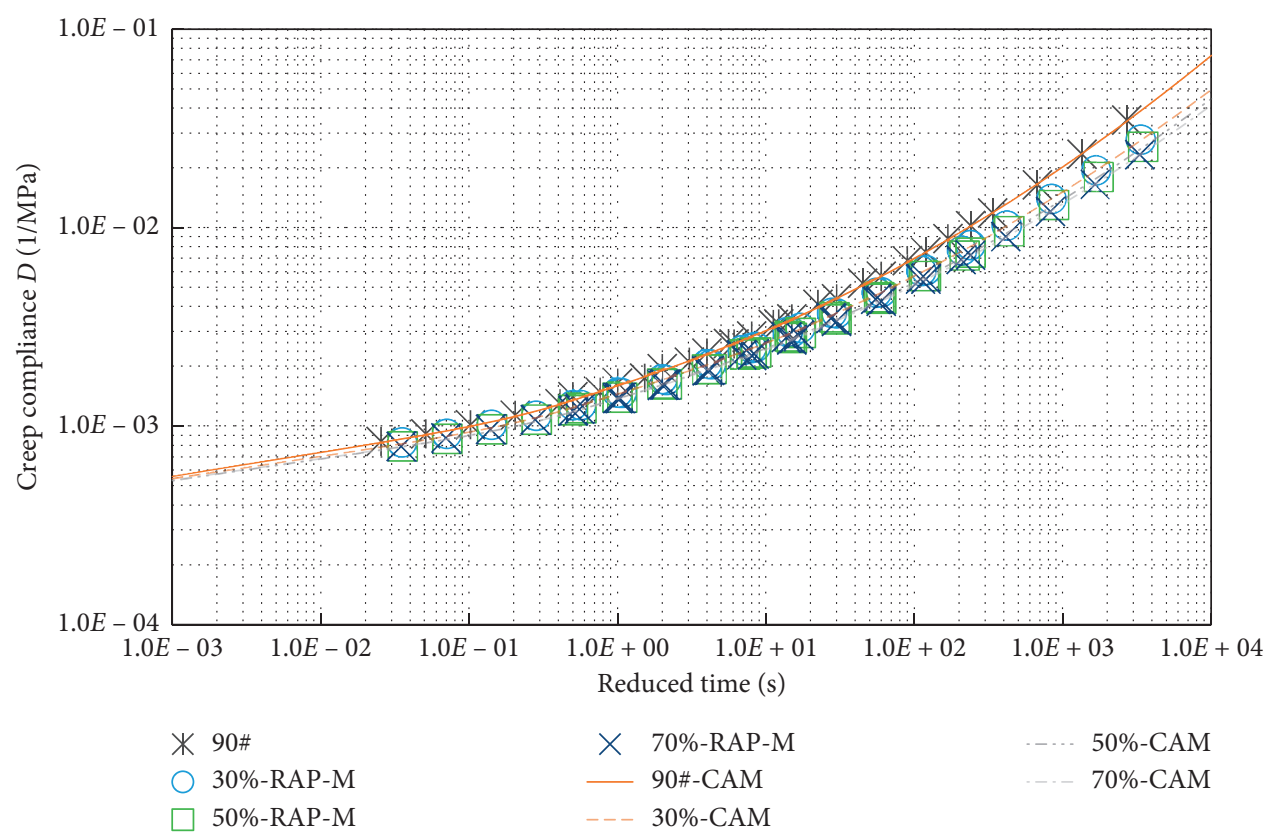

(b)

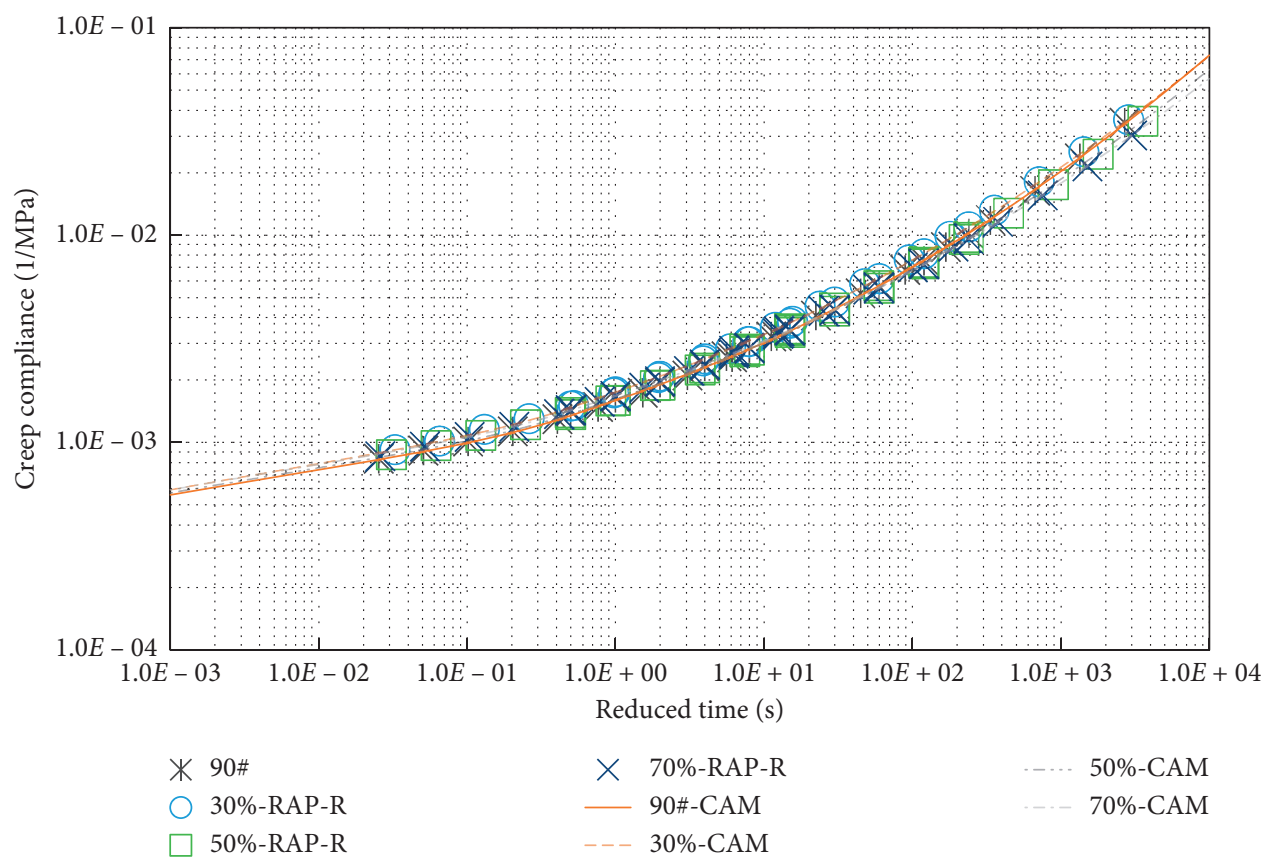

(c)

FIgURE 14: Master curves from the CAM model for BBR data of three types of recycled binders. (a) Control binder, (b) RAP-M binder, and (c) RAP-M binder.

Therefore, the performances at low temperature of RAP-R and RAP-M binders are both improved. In addition, the increased content of RAP binder decreases the viscous property of asphalt, prolongs the relaxation time of stress, and reduces the low-temperature crack resistance.

3.3. Analysis of MSCR Test Results. A comparative analysis is first made based on the test results of the recycled binder with $50 \%$ of RAP binder at $3.2 \mathrm{kPa}$, as shown in Figures $17(\mathrm{a})$ and $17(\mathrm{~b})$.
Figure 17(a) shows the strain-time curve of the control binder with $50 \%$ of RAP binder at different test temperatures. As the temperature increases, the strain increases significantly at a growing rate. When the temperature is up to $64^{\circ} \mathrm{C}$, the strain is the largest, and there is no distinct recovery under each cycle of loading and unloading. It indicates that the elastic component of the control binder has nearly disappeared at $64^{\circ} \mathrm{C}$.

Figure 17(b) gives the strain-time curve of the three types of recycled binder at $46^{\circ} \mathrm{C}$. During the MSCR test, two 


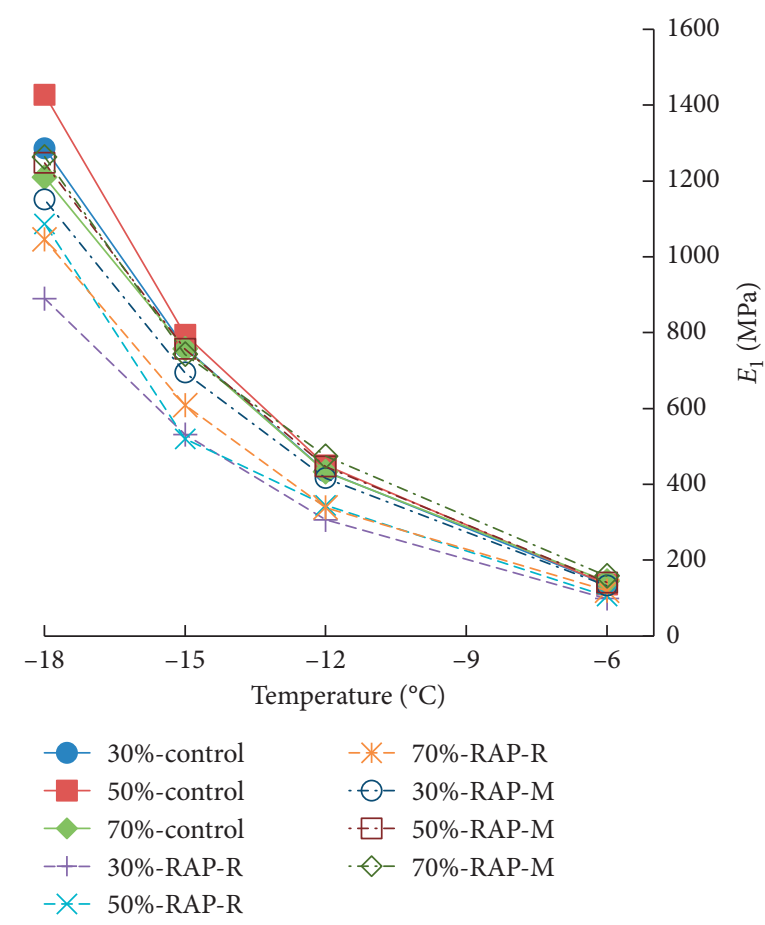

(a)

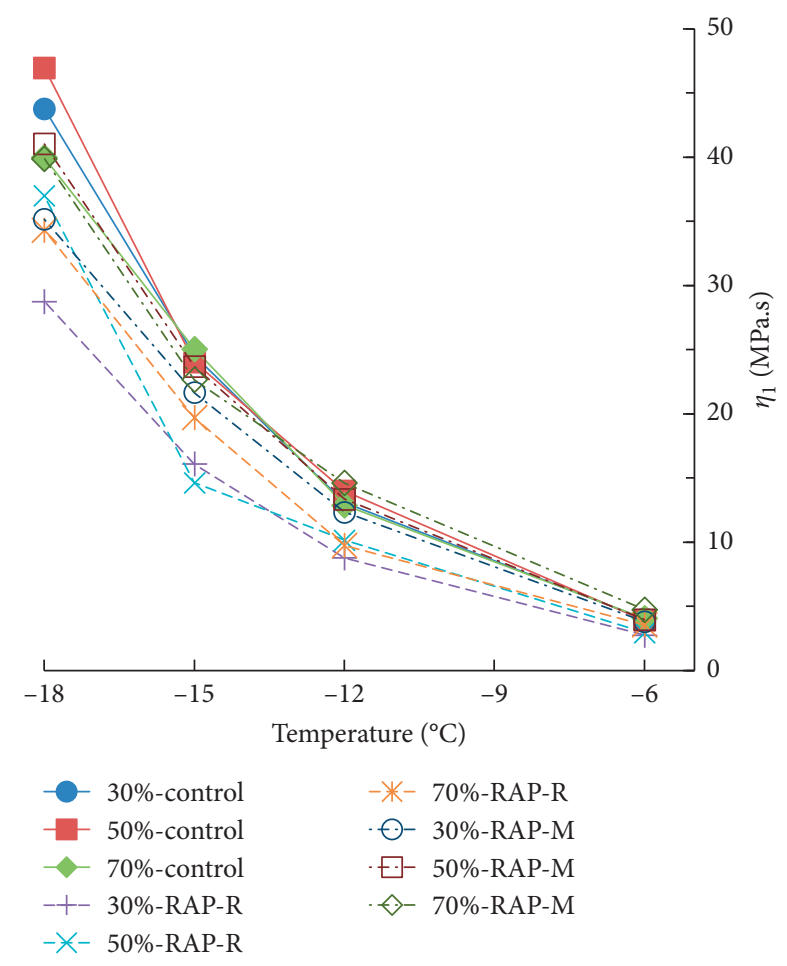

(c)

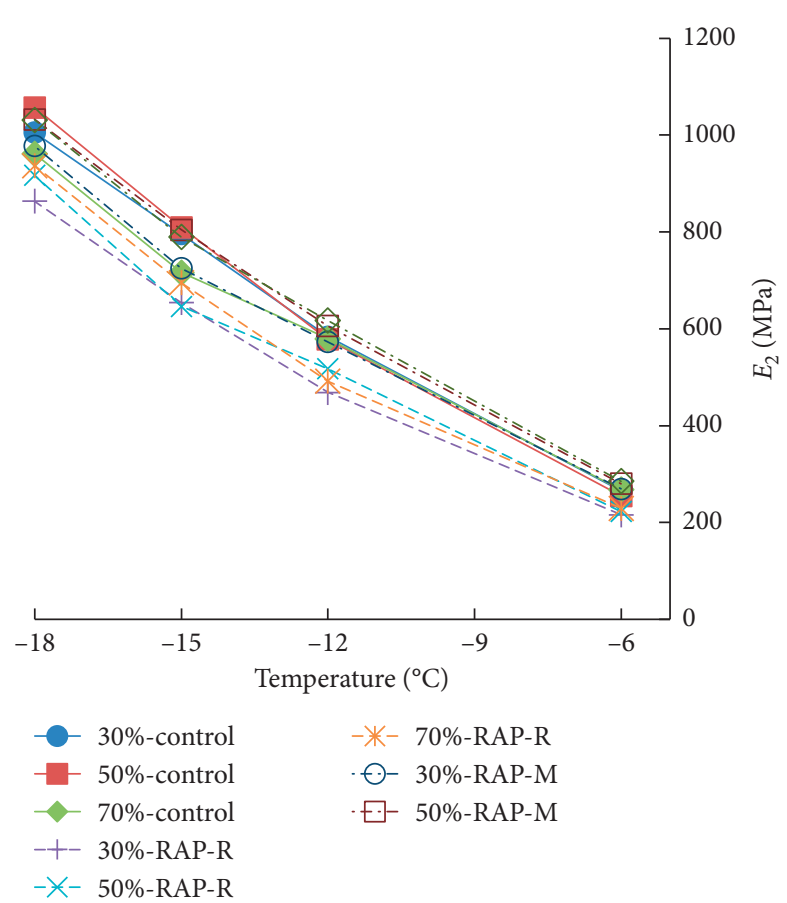

(b)

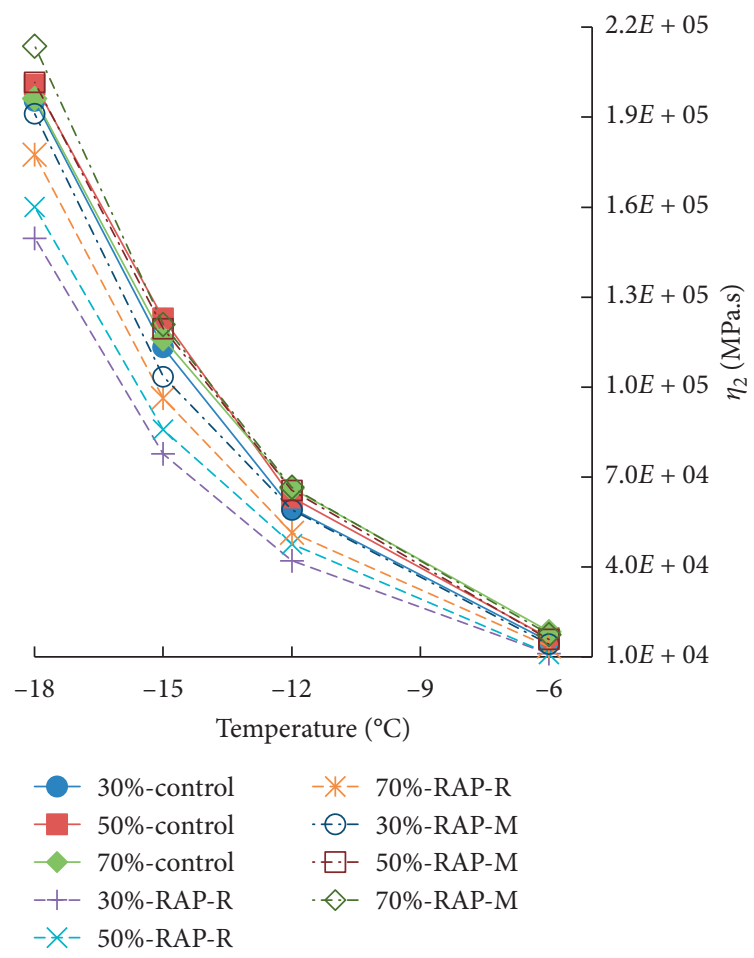

(d)

FIGURe 15: Parameters of Burgers' model for WMRA binders at various temperatures. (a) Delayed elastic parameter $E_{1}$. (b) Instant elastic parameter $E_{2}$. (c) Delayed viscous parameter $\eta_{1}$. (d) Viscous flow parameter $\eta_{2}$.

loads at different stress levels were applied to simulate different loads on the real pavement due to diverse traffic volumes. As a result, the difference in deformation can exhibit the antideformation property. The strains of the three types of recycled binders are ranked as follows: RAP-
$\mathrm{R}>$ control $>\mathrm{RAP}-\mathrm{M}$, which indicates that the addition of $\mathrm{M}$ enhances the antideformation property of the recycled binder, while the addition of $R$ has an opposite effect. At high temperatures, the addition of $R$ makes the recycled binder more like a viscous fluid. 


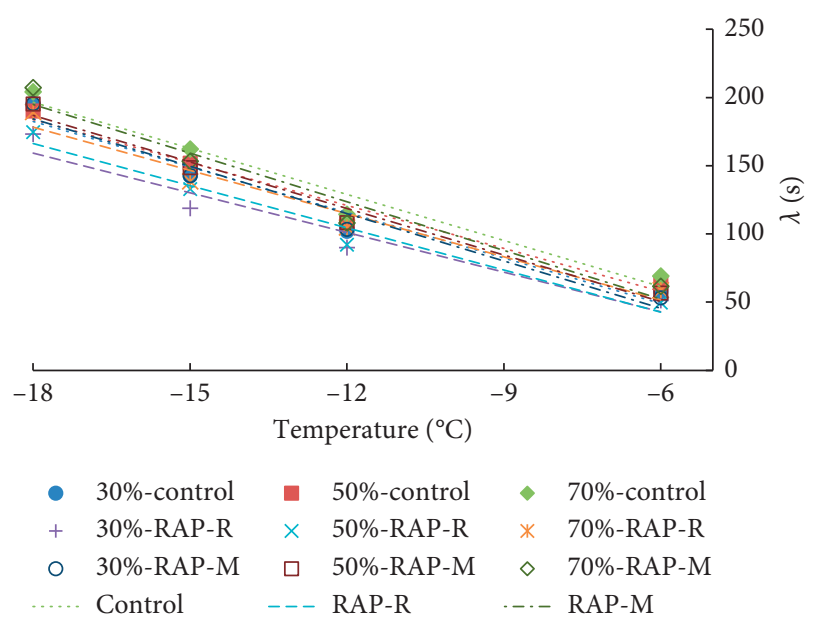

Figure 16: Relationship of relaxation time $\lambda$ and temperature.

TABLE 2: Linear regression function and correlation coefficients between relationship of relaxation time $\lambda$ and temperature.

\begin{tabular}{lccccc}
\hline Control (\%) & Functions and $R^{2}$ & RAP-R (\%) & Functions and $R^{2}$ & RAP-M (\%) & Functions and $R^{2}$ \\
\hline 30 & $y=-\begin{array}{l}11.135 x-17.901 ; \\
R^{2}=0.9560\end{array}$ & 30 & $\begin{array}{c}y=-9.6889 x-15.205 ; \\
R^{2}=0.9342\end{array}$ & 30 & $y=-11.569 x-23.828 ; R^{2}=0.9663$ \\
\hline 50 & $y=-\begin{array}{l}10.486 x-4.8829 ; \\
R^{2}=0.9765\end{array}$ & 50 & $\begin{array}{c}y=-10.3 x-19.091 ; \\
R^{2}=0.9680\end{array}$ & 50 & $y=-11.377 x-17.876 ; R^{2}=0.9778$ \\
\hline 70 & $y=-\begin{array}{c}11.245 x-5.972 ; \\
R^{2}=0.9679\end{array}$ & 70 & $\begin{array}{c}y=-10.551 x-11.693 ; \\
R^{2}=0.9619\end{array}$ & 70 & $y=-11.882 x-19.037 ; R^{2}=0.9557$ \\
\hline
\end{tabular}

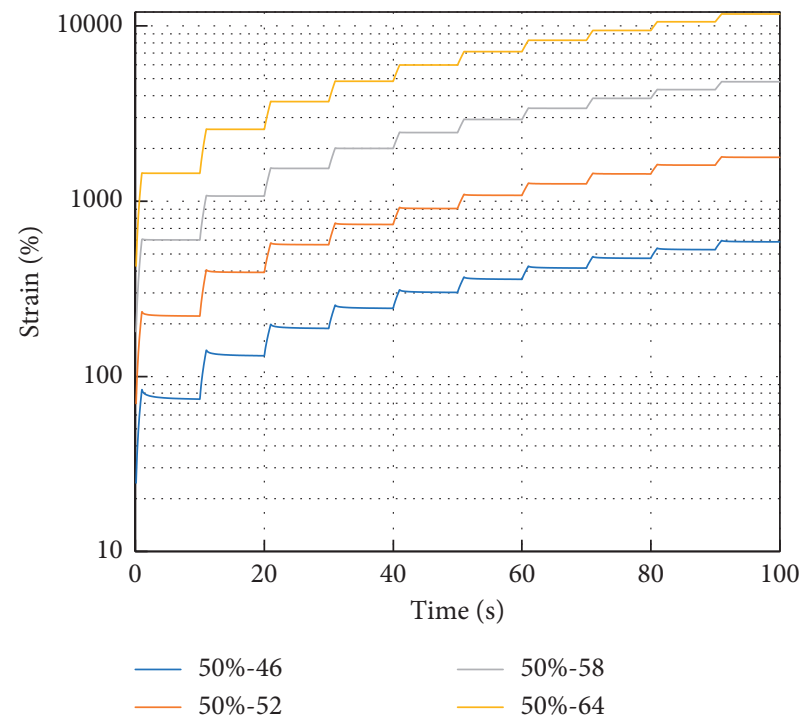

(a)

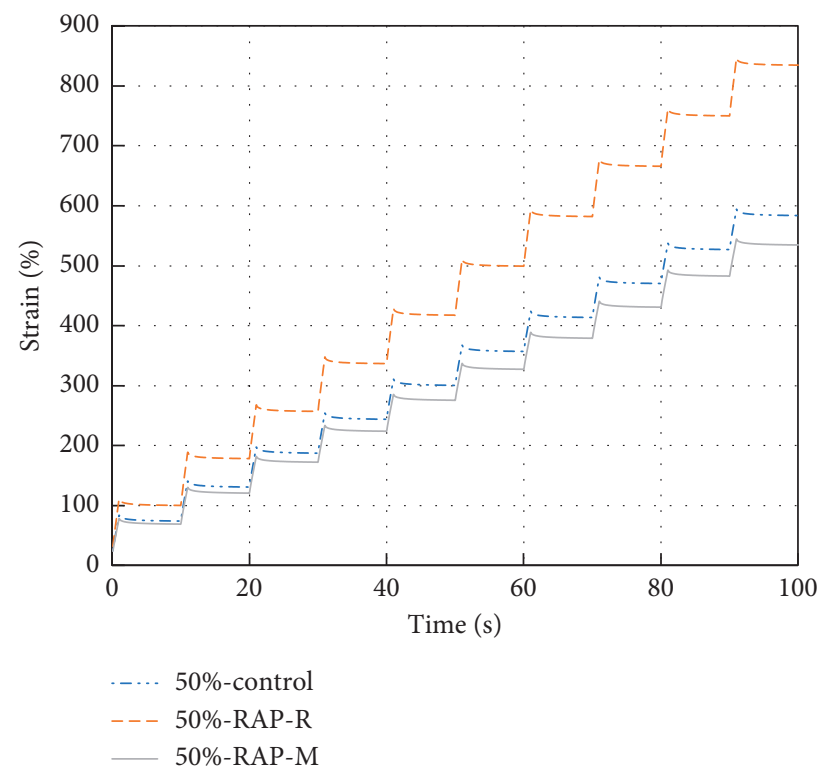

(b)

FIGURE 17: Strains curve of MSCR: (a) various temperatures and (b) various recycled binders. 


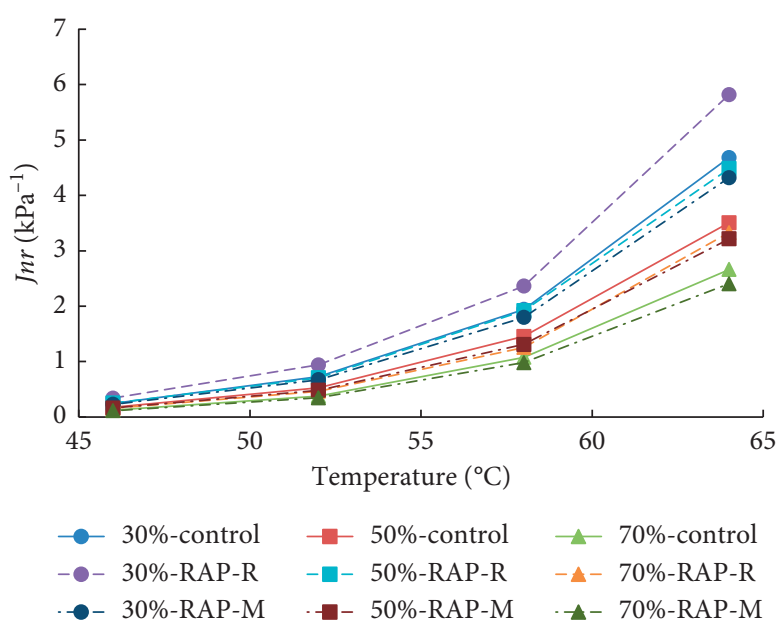

(a)

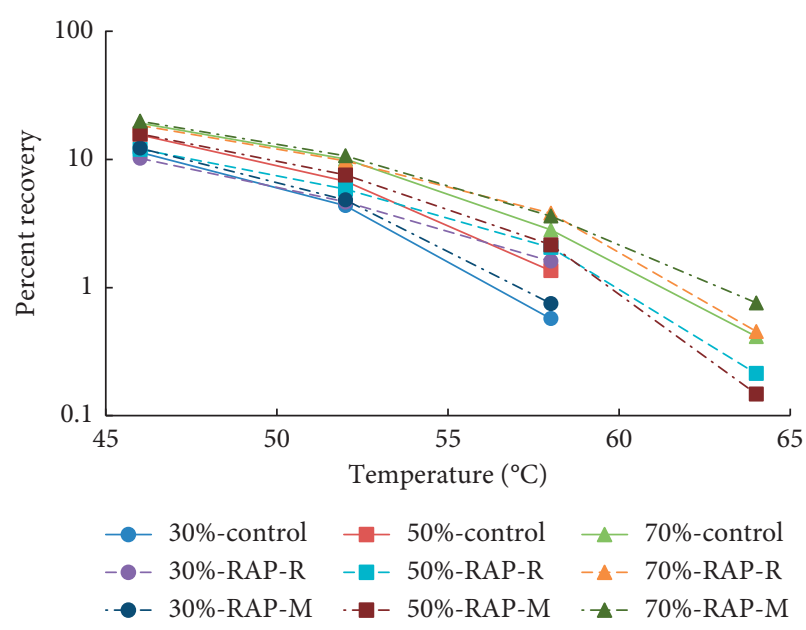

(b)

FIGURE 18: MSCR parameters of three types of recycled binders: (a) $J_{n r}(\mathrm{k} / \mathrm{Pa})$ and (b) $\mathrm{R}(\%)$.

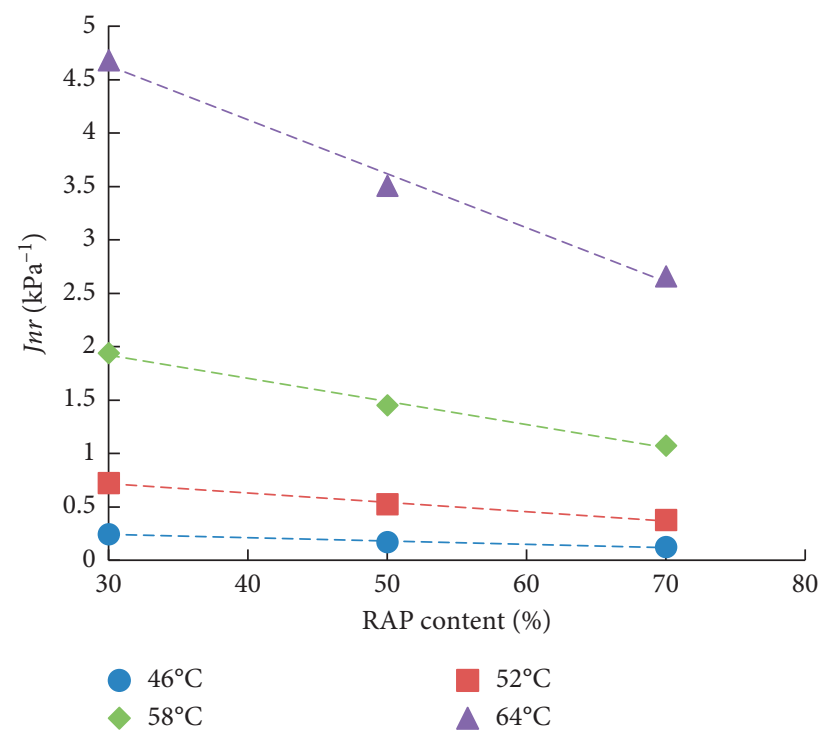

(a)

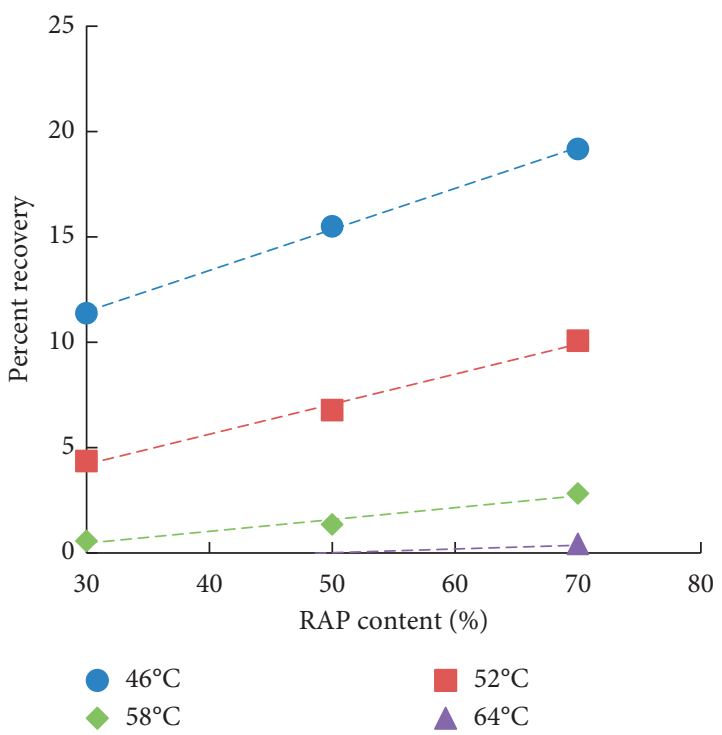

(b)

FIGURE 19: Relationship of aging asphalt content and MSCR parameters for control binders: (a) unrecoverable creep compliance and (b) creep percent recovery.

The unrecoverable creep compliance $J_{n r}$ and percent recovery $\mathrm{R}$ of recycled asphalt binders at $3.2 \mathrm{kPa}$ at the four temperatures are shown in Figures 18(a)-18(b).

The creep percent recovery represents the elastic deformation capacity of asphalt binders. The creep percent recovery of the recycled binders with different RAP binder contents at different temperatures are shown in Figure 18(b). The results of recycled binders containing 30\% RAP binder are not shown in Figure 18(b), as their percent recovery is close to 0. By comparison, it can be found that the creep percent recovery of the RAP-M binder is higher than that of control and RAP-R binders under the same condition; therefore, RAP-M binder is more suitable for high-temperature regions. Although the addition of $\mathrm{R}$ leads to a minimum percent recovery, the combined use of RAP binder can offset its disadvantage in the high-temperature performance. Moreover, RAP-R binder has the best lowtemperature performance; thus, it can be introduced in colder regions. Despite the fact that the creep percent recovery represents the viscoelastic deformation capacity of asphalt binders, the accumulation of final permanent deformation depends primarily on the unrecoverable compliance $\left(J_{n r}\right)$. Through the comparison from Figure 18(a), the antipermanent deformation capacity of the three types of 


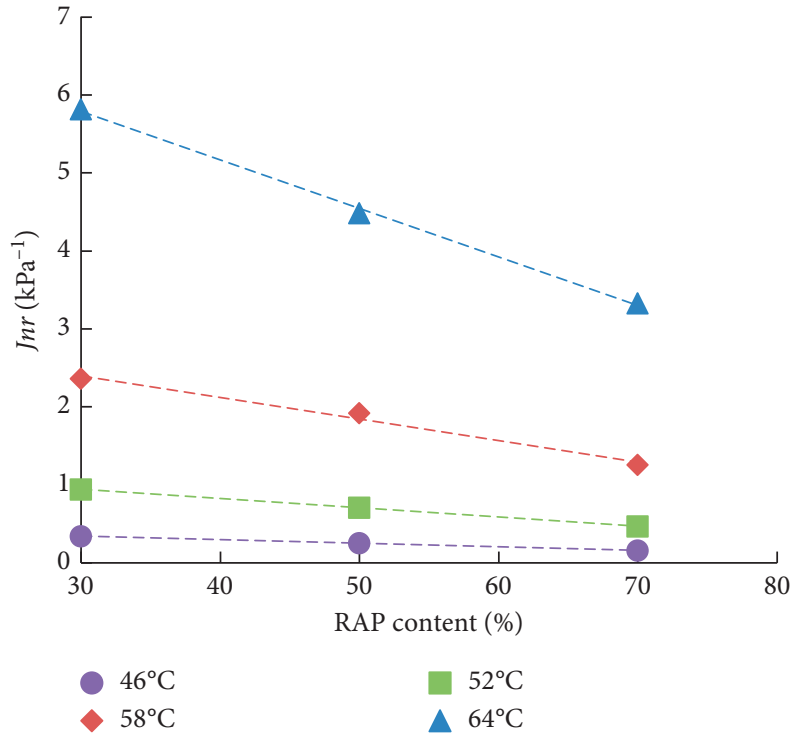

(a)

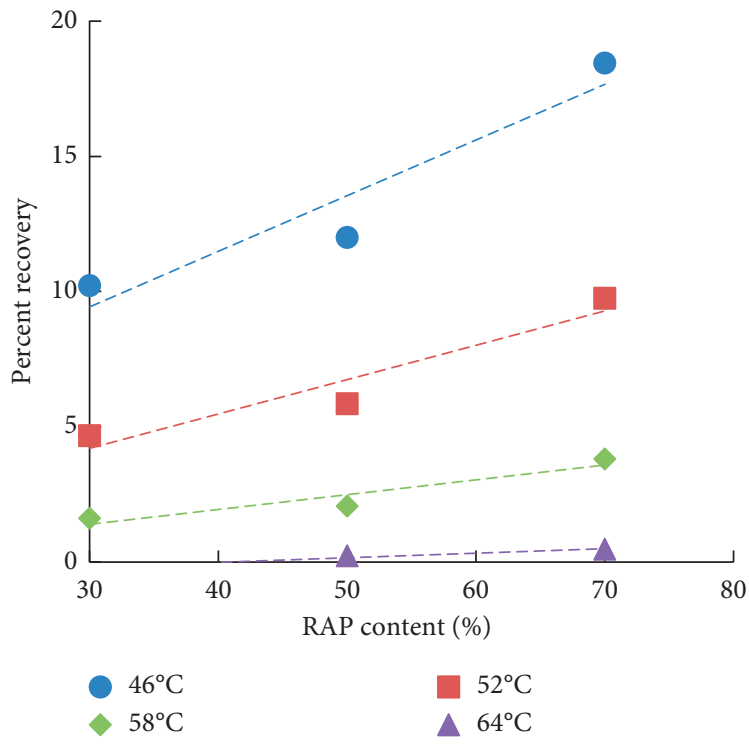

(b)

FIGURE 20: Relationship of aging asphalt content and MSCR parameters for RAP-R binders: (a) unrecoverable creep compliance and (b) creep percent recovery.

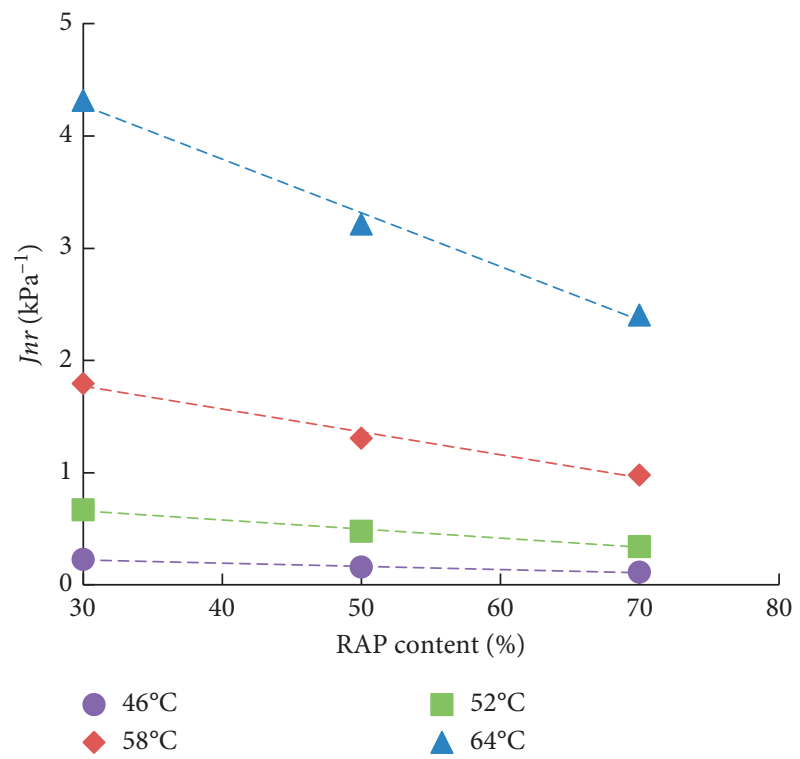

(a)

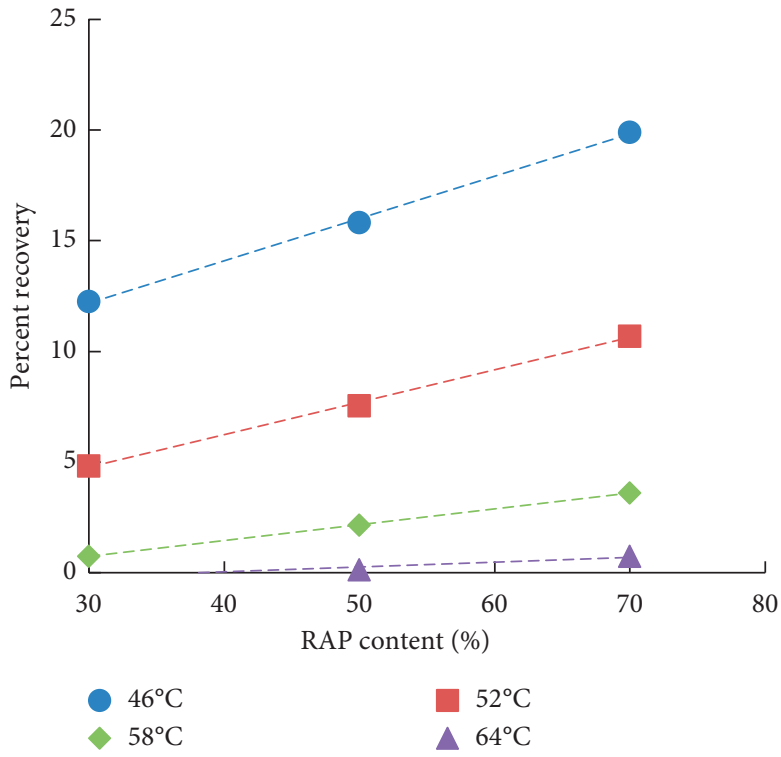

(b)

FIGURE 21: Relationship of aging asphalt content and MSCR parameters for RAP-M binders: (a) unrecoverable creep compliance and (b) creep percent recovery.

recycled binder under the same condition is RAP$\mathrm{M}>$ control $>$ RAP-R.

The increment of RAP binder content of recycled binder can reduce the unrecoverable creep compliance $\left(J_{n r}\right)$ and improve the creep percent recovery R. The relationships between $J_{n r}$ and R and RAP binder content are shown in Figures 19-21. It can be observed that there is a good linear relation displayed between the RAP binder content and either $J_{n r}$ or R. As the temperature increases, the impact of RAP binder content on $J_{n r}$ and $R$ decreases at a growing rate. Therefore, $J_{n r}$ and $\mathrm{R}$ can be predicted based on the figures of the recycled binders containing different contents of RAP binder, which is able to assess the actual high-temperature pavement performance of high-percentage WMRA. Meanwhile, on the premise of satisfying low-temperature and fatigue performance, increasing the RAP binder content can improve not only the recycling efficiency and high-temperature performance but also the requirements of traffic volume level for the WMRA pavement. 


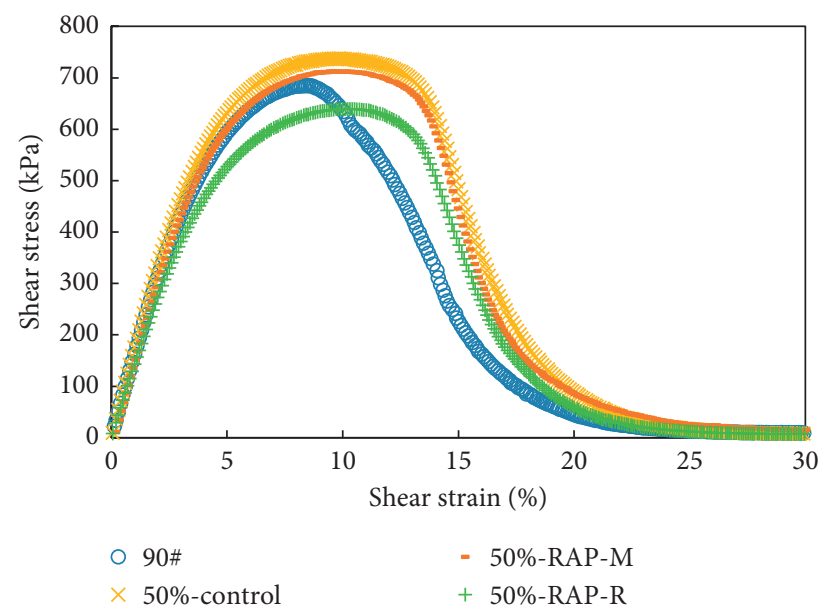

FIgURE 22: Shear stress and phase angle of LAS test.

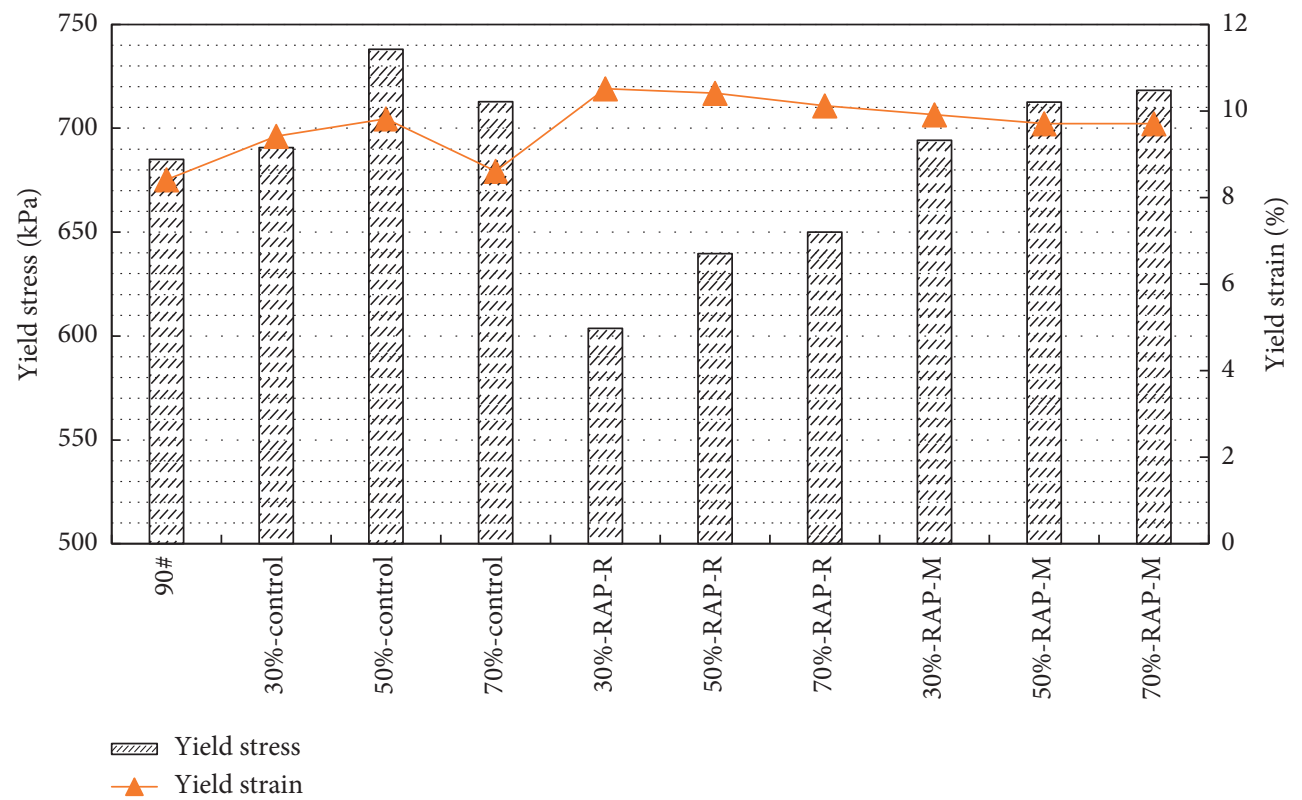

FIgURE 23: Comparison between yield stress and yield strain of various recycled binders.

3.4. Analysis of LAS Fatigue Characteristics. Similar trends are observed for different artificial RAP contents; thus, only the recycled binders containing 50\% artificial RAP binder are typically presented in Figure 22. The dependency of asphalt materials on the applied strain and the damage induced under loading can be exhibited from the shear stress and strain curve in Figure $22[49,50]$. According to the peak shape of the shear stress and strain curve, the two types of WMRA binders have relatively wider peaks, indicating that the combined use of the RAP binder and WMA additives lowers the dependency of asphalt binder on the strain; thus, the antifatigue performance of WMRA binder is improved. In contrast, the 90\# base asphalt has a relatively narrower peak, so the antifatigue performance is slightly reduced compared with the two types of WMRA binders.
The yield stresses and yield strains of the asphalt binders are obtained from the shear stress and strain curves in Figure 22, and the results are shown in Figure 23.

The yield stresses of the 10 asphalt samples at $20^{\circ} \mathrm{C}$ are ranked as follows: 50\%-control $>70 \%$-RAP-M $>50 \%$-RAP$\mathrm{M} \approx 70 \%$-control $>30 \%$-RAP-M $>30 \%$-control > 90\# > 70\%RAP-R > 50\%-RAP-R > 30\%-RAP-R. Meanwhile, the yield strains are $30 \%$-RAP-R $>50 \%$-RAP-R $>70 \%$-RAP-R $>30 \%$ RAP-M $>50 \%$-control > 50\%-RAP-M $\approx 70 \%$-RAP-M $>30 \%$ control $>70 \%$-control $>90 \#$. Compared with $90 \#$ base asphalt, the yield stress and yield strain of the control binder are improved due to the addition of RAP binder, which exhibits an obvious peak value with the increase of the RAP binder content. Incorporating the two types of WMA additives, the yield stress and yield strain of WMRA binders show a regular change as the RAP binder content increases. The RAP binder 


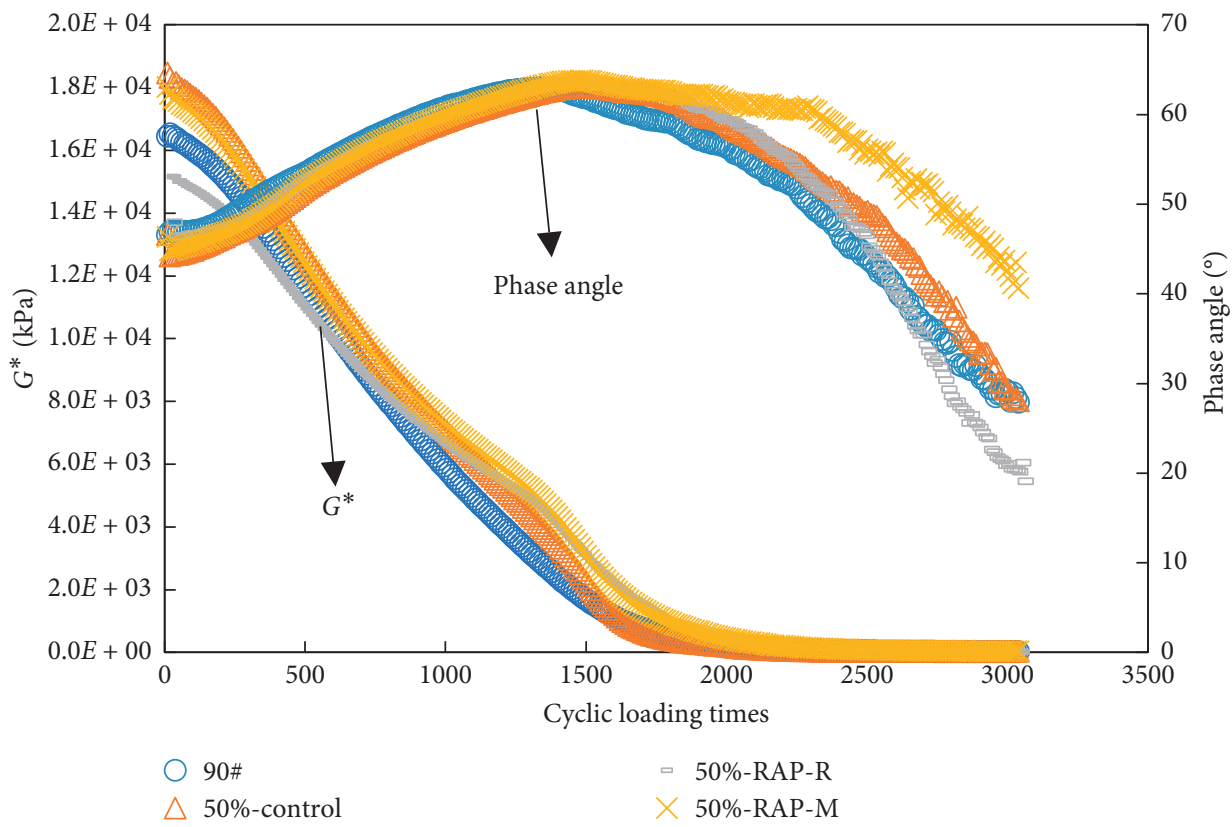

FIGURE 24: Relationship between complex shear modulus or phase angles and cyclic loading times.

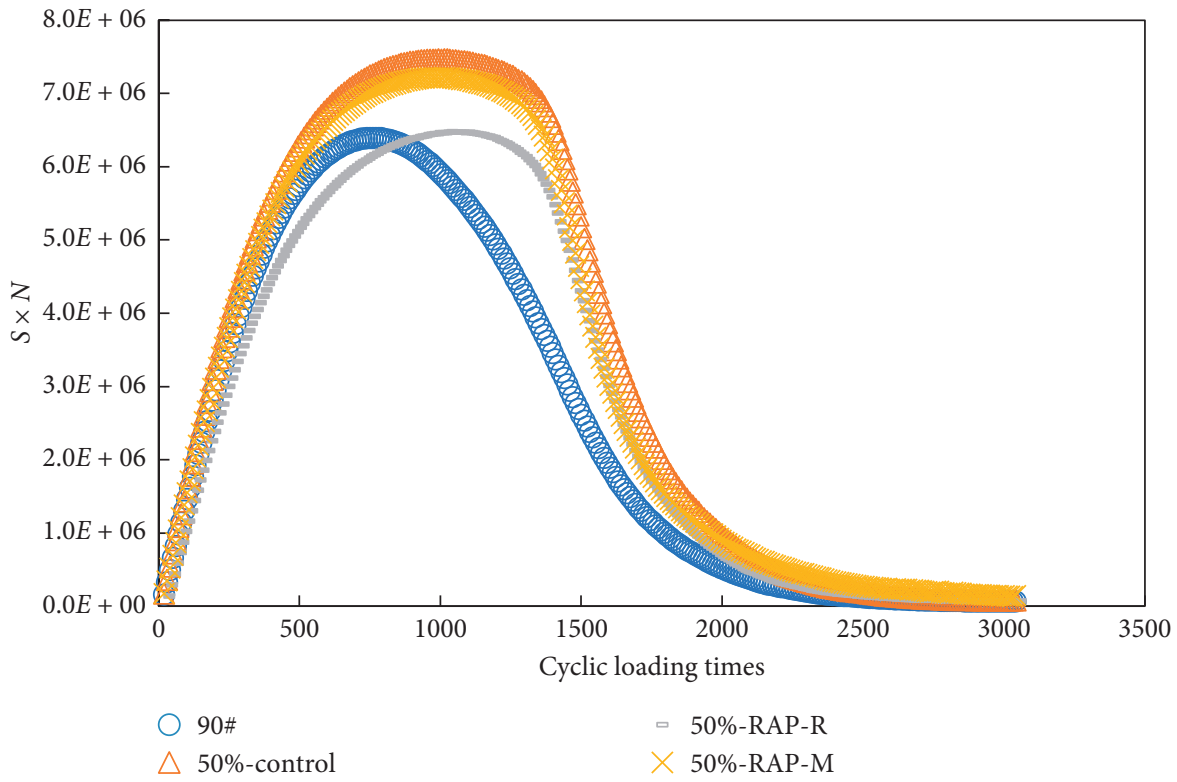

FIgURE 25: Relationship between $S \times N$ values and cyclic loading times.

content is positively correlated to the yield stress and negatively correlated to the yield strain. The yield stress is reduced and the yield strain is increased with the incorporation of $\mathrm{R}$ comparing with other asphalt binders, which suggests that the antideformation property of RAP-R binder is weakened, while the addition of $\mathrm{M}$ can improve the antideformation property and deformation extent of the recycled binder.
However, the increment of the RAP binder content has no significant impact on the recycled binder on the whole with the action of $\mathrm{M}$.

In this paper, three methods were adopted to evaluate the fatigue failure of high-percentage WMRA binders: (1) the modulus decreasing to $50 \%$ of the initial value; (2) the peak of phase angle; and (3) the peak of $S \times N$ index, where $S$ is the 


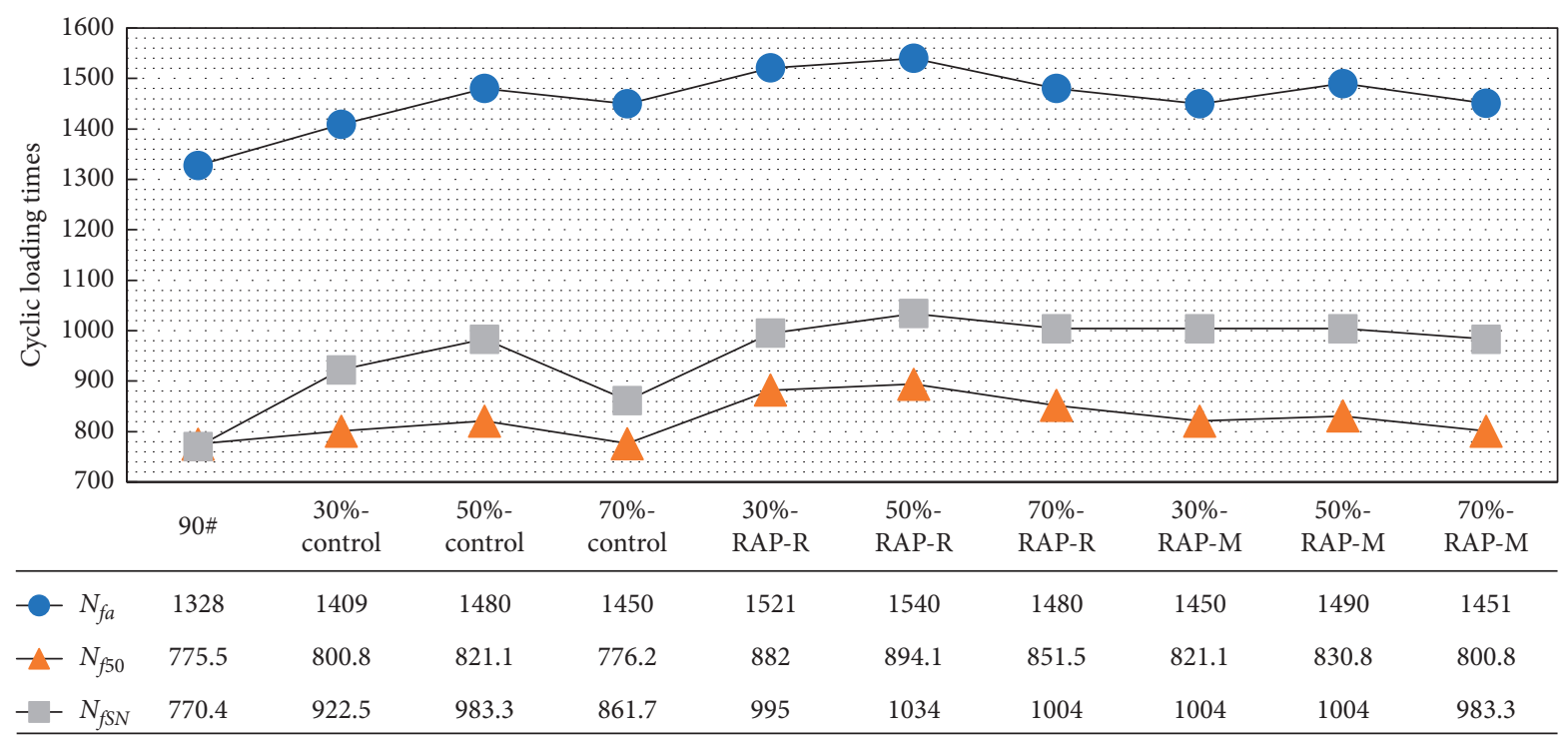

FIgURE 26: Fatigue life results of the three methods.

ratio of the instantaneous modulus to the initial modulus and $N$ is the loading times [51]. The relation curve between each of the three methods and the cyclic loading times is plotted, respectively, as shown in Figures 24 and 25.

The fatigue lives, calculated using the three methods, are denoted as $N_{f 50}, N_{f a}$, and $N_{f S N}$, respectively, and are shown in Figure 26.

In Figure 26, the fatigue lives of asphalt binders of the three methods are ranked as $N_{f a}>N_{f S N}>N_{f 50}$. The difference between the fatigue lives can be ascribed to the fact that the fatigue failure obtained through the three methods corresponding to the process of fatigue failure is varied. However, the changing tendencies of fatigue lives of the 10 asphalt binders obtained by the three methods are almost the same, indicating that the influence of the RAP binder content and WMA additives on the antifatigue performance of recycled binders is almost the same in the process of fatigue failure. In general, the additions of $\mathrm{R}$ and $\mathrm{M}$ both improve the fatigue life of recycled asphalt binders, while the effect of $\mathrm{R}$ is more noticeable. The RAP binder contents have different effects on different recycled asphalt binders, which indicates that the evaluation of fatigue failure of recycled asphalt binders, especially highpercentage WMRA binder, is comparatively complex considering the combined use of RAP binder and WMA additive.

Then, the VECD model is employed to analyze the LAS test results, and the parameters are shown in Table 3.

The integrity parameter $C$ represents the damage degree of the asphalt material. When $C$ is equal to 1 , the material is intact. When $C$ is equal to 0 , the material has been completely damaged [44]. According to (15), the damage characteristic curve of three types of recycled binder with different contents of RAP binder can be obtained, as shown in Figures $27(\mathrm{a})-27(\mathrm{c})$, to evaluate the antifatigue performance of the recycled binder. In Figure 27(a), the curve of $70 \%$-control binder is close to that of $90 \#$ base asphalt. The curves of 30\%-control binder and 50\%-control binder are above that of $90 \#$ base asphalt when the damage intensity is larger than 60 , indicating that the damage of $30 \%$-control and 50\%-control binder is slower than that of 90\# base asphalt. The damage curves of RAP-R and RAP-M binders are shown in Figures 27(b) and 27(c). With the combined use of RAP binder and WMA additive, the curves of RAP-R and RAP-M binders are above that of 90\# base asphalt, indicating that the addition of RAP binder will not reduce the antifatigue performance of the asphalt binder; instead, the performance can be further enhanced by adding the WMA additive, $\mathrm{R}$ in particular.

The parameter $\alpha$ represents the slope of the fatigue life and the strain in the log-coordinate. The larger the $\alpha$, the more sensitive the fatigue life to strain. Table 3 illustrates that $\alpha$ of $90 \#$ base asphalt is the smallest and that of the three types of recycled binder increases as the RAP binder content increases, indicating that the recycled asphalt binder is more sensitive to the applied strain with the incorporation of RAP binder. $\alpha$ is ranked as follows: RAP-R $<$ RAP-M $<$ control, containing the same RAP binder content, indicating that the addition of WMA additive makes the asphalt binder less sensitive to the strain.

According to (18) and (19), the fatigue lives with different strains $(1 \%, 3 \%$, and $5 \%)$ can be obtained, as shown in Figures 28-30.

The three figures show that as the strain level increases, the fatigue life of the asphalt binders gradually decreases. The fatigue life of the three types of recycled asphalt binder with $50 \%$ of RAP binder presents a peak value, indicating that the current fatigue life is the highest in this regard, especially at high strain level. This is consistent with the previous study in Figure 28. Therefore, emphasis must be placed on the fact 
TABLE 3: Resulting parameters of the VECD model.

\begin{tabular}{|c|c|c|c|c|c|c|}
\hline Type of asphalt & $\alpha$ & $C_{0}$ & $C_{1}$ & $C_{2}$ & $A$ & $B$ \\
\hline $90 \#$ & 1.49276 & 1 & 0.10296 & 0.4175 & $1.52 E+05$ & 2.98552 \\
\hline $30 \%$-control & 1.573317 & 1 & 0.10953 & 0.39992 & $3.68 E+05$ & 3.146633 \\
\hline $50 \%$ - control & 1.614987 & 1 & 0.10154 & 0.40942 & $5.64 E+05$ & 3.229974 \\
\hline $70 \%$ - control & 1.666944 & 1 & 0.10809 & 0.4076 & $3.85 E+05$ & 3.333889 \\
\hline $30 \%-R A P-R$ & 1.510802 & 1 & 0.0991 & 0.41276 & $3.75 E+05$ & 3.021604 \\
\hline $50 \%$-RAP-R & 1.577785 & 1 & 0.08369 & 0.44346 & $5.38 E+05$ & 3.15557 \\
\hline 70\%-RAP-R & 1.60901 & 1 & 0.10124 & 0.40828 & $4.85 E+05$ & 3.218021 \\
\hline $30 \%-R A P-M$ & 1.547988 & 1 & 0.10309 & 0.41102 & $3.77 E+05$ & 3.095975 \\
\hline 50\%-RAP-M & 1.608493 & 1 & 0.11199 & 0.39416 & $5.40 E+05$ & 3.216986 \\
\hline 70\%-RAP-M & 2.656452 & 1 & 0.11497 & 0.38876 & $6.08 E+05$ & 3.312904 \\
\hline
\end{tabular}

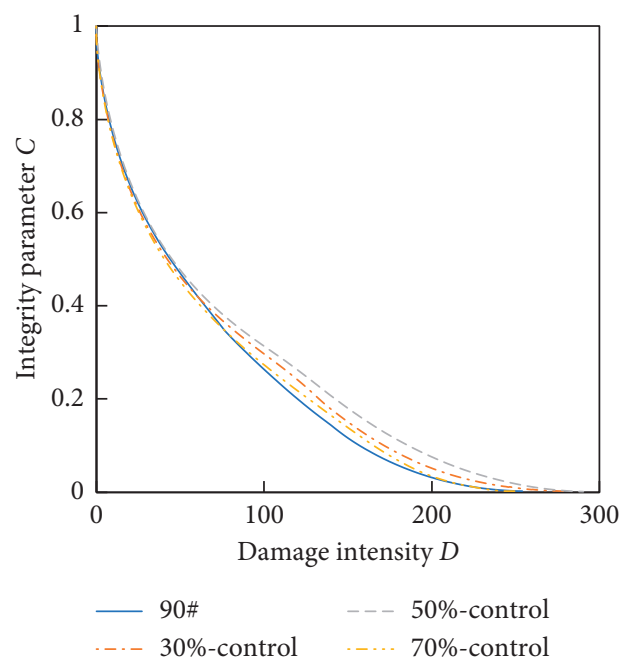

(a)

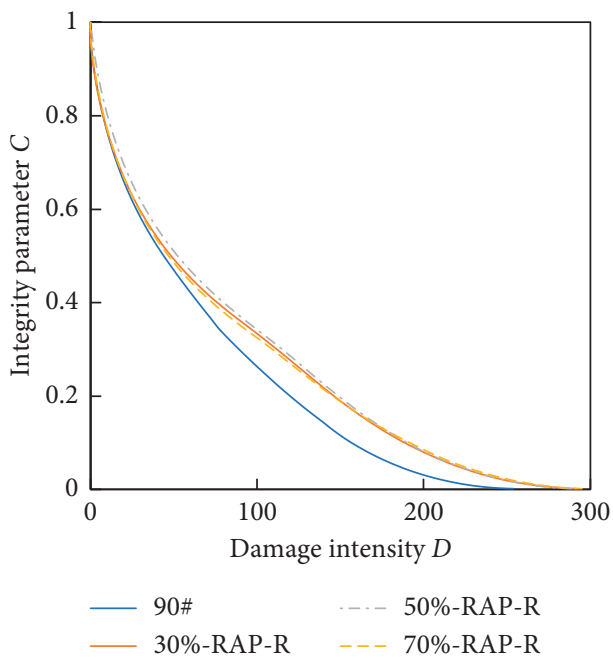

(b)

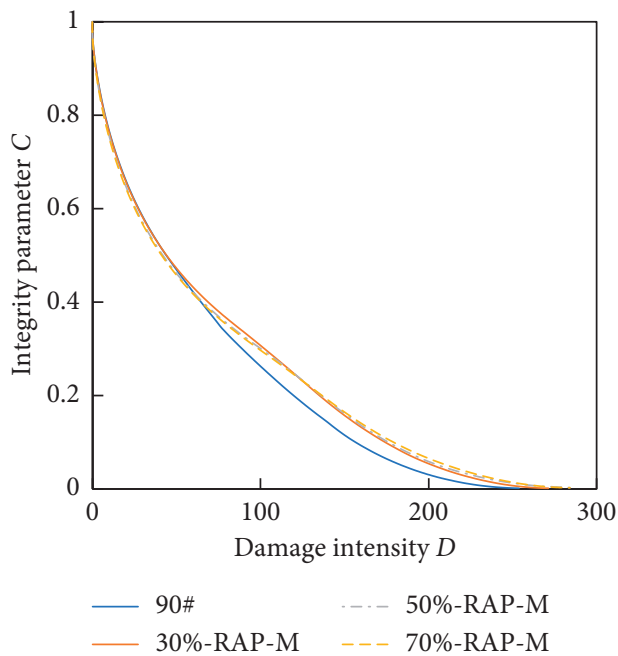

(c)

FIgURE 27: Typical damage plots for various recycled binders. (a) Control binder; (b) RAP-R binder; and (c) RAP-M binder.

that when the RAP content is more than $50 \%$, the fatigue performance will be reduced. However, even though the percentage of RAP binder is high, the fatigue life is still longer than that of $90 \#$ base asphalt. Moreover, comparing with the control binder, the fatigue life is improved due to the addition of two types of WMA additives. As a result, the antifatigue performance of high-percentage WMRA binders can satisfy the requirements of pavement. 


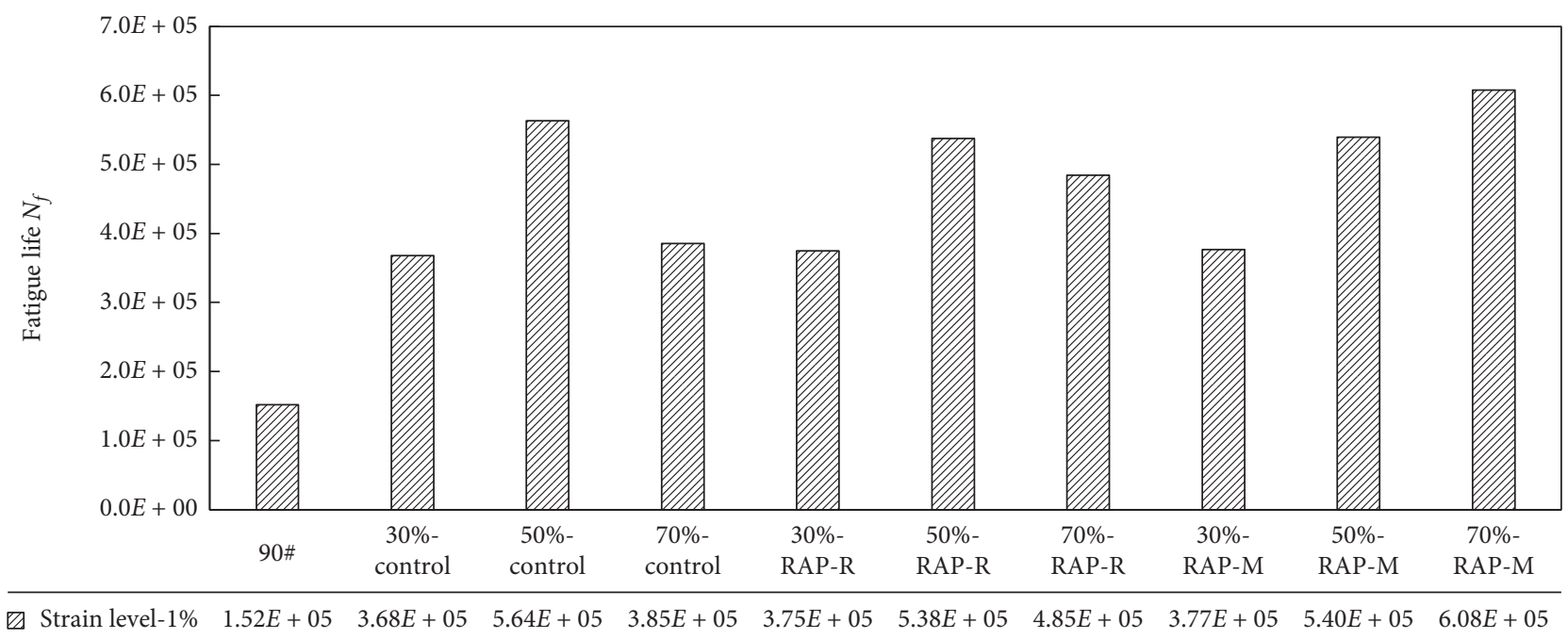

Figure 28: $N_{f}$ at applied strain level of $1 \%$ for various asphalt binders.

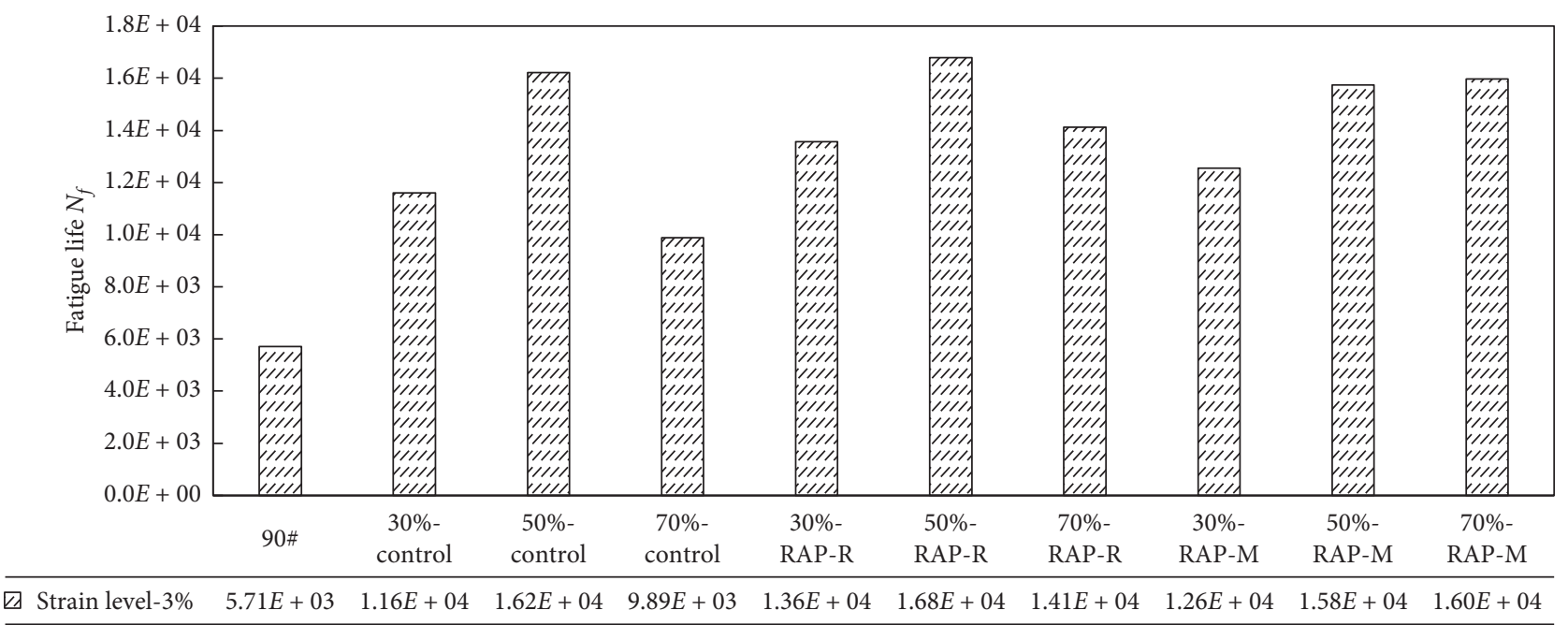

FIgUre 29: $N_{f}$ at applied strain level of $3 \%$ for various asphalt binders.

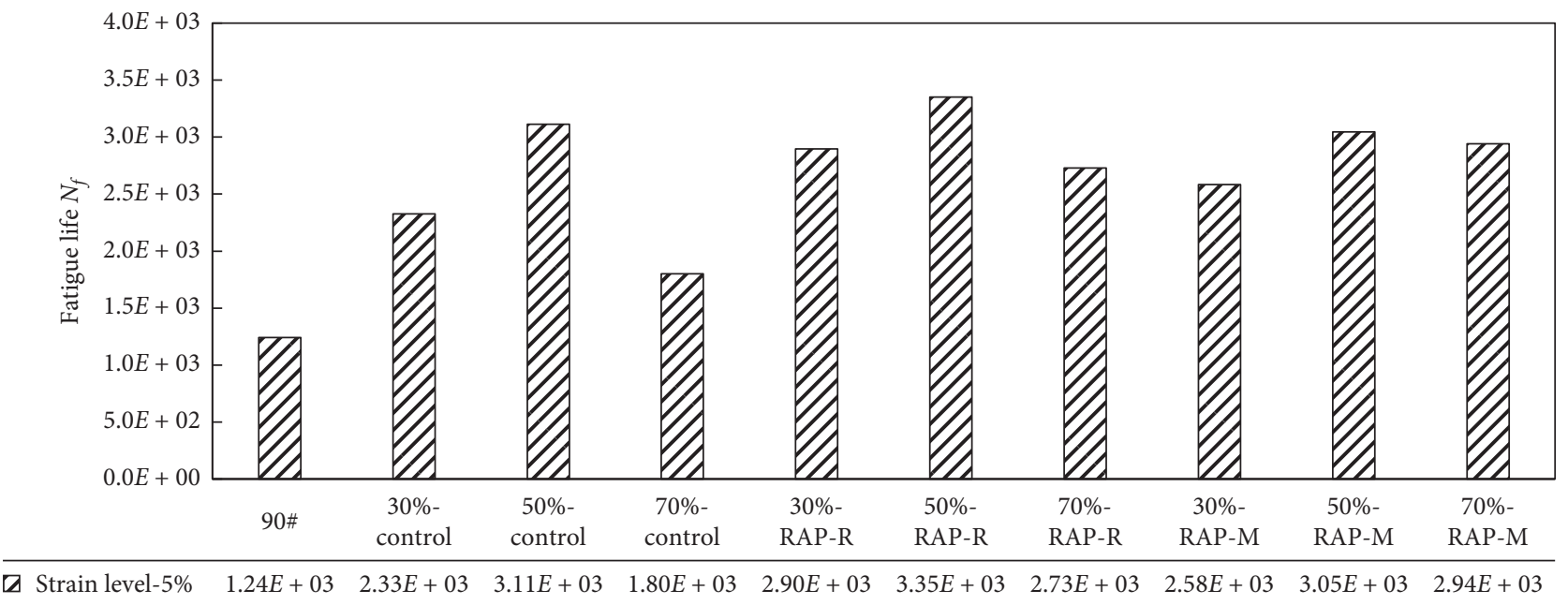

FIgURE 30: $N_{f}$ at applied strain level of $5 \%$ for various asphalt binders. 


\section{Conclusions}

Based on the observations and analyses from this study, the main conclusions can be drawn as follows:

(1) The addition of WMA additive R reduced the antideformation property of asphalt binders, and the viscoelasticity of RAP-R binder changed remarkably before aging, while the addition of WMA additive $\mathrm{M}$ had little impact on the rheological property of asphalt

(2) Regardless of whether subjected to long-term aging or not, the RAP binder content had no significant effect on the rheology property of WMRA binders. It presents a bad fitting of phase angle using 2S2P1D model, especially for the RAP-R binder with $50 \%$ and $70 \%$ RAP binder contents

(3) The performance of low-temperature crack resistance of recycled binders was reduced comparing with the 90\# base asphalt, due to the addition of RAP binder. The low-temperature performance of the three types of recycled binders was ranked as RAP-R binder $>$ RAP-M binder $>$ control binder

(4) It should be noted that in terms of master curves of creep compliance, with the increase of the RAP binder content, the creep compliance changed slightly, whereas considering the parameters analysis of Burgers' model, the performance of low-temperature crack resistance was reduced with the increase of the RAP binder content

(5) The antideformation property of recycled binders was enhanced with the addition of RAP binder. In terms of $J_{n r}$ and R at $3.2 \mathrm{kPa}$ from the MSCR test, the antideformation property and elasticity of RAP-M binder were better than control and RAP-R binders, while the addition of WMA additive $\mathrm{R}$ remarkably lowered the rutting resistance

(6) There were both good linear relationships between the RAP binder content of the three types of recycled binder and $J_{n r}$ or R. Furthermore, the increment of RAP binder content of recycled binder can reduce the unrecoverable creep compliance $\left(J_{n r}\right)$ and improve the creep percent recovery $\mathrm{R}$

(7) The addition of RAP binder could not reduce the antifatigue performance of recycled asphalt binders, but there were different effects on the three types of recycled asphalt binders depending on the change of RAP binder content. The fatigue life of recycled asphalt binders was improved with the incorporation of WMA additives $\mathrm{R}$ and $\mathrm{M}$, and the effect of WMA additive $R$ was more significant

(8) The Nf predicted-based VECD method presents a peak value when the RAP binder content is $50 \%$ for all the three types of WMRA binders. Therefore, emphasis must be placed on the fact that when the RAP content is more than $50 \%$.
It should be mentioned that further research needs to be carried out to explain some results obtained from this paper, such as selecting another model to fit the phase angle of WMRA binders more accurate and exploring the components of WMA additive R to explain the WMA mechanism. Besides, the RAP binder extracted from the milling asphalt pavement should be recycled comparing with the conclusions of this research.

\section{Data Availability}

The data used to support the findings of this study are available from the corresponding author upon request.

\section{Conflicts of Interest}

The authors confirm that there are no conflicts of interest regarding the publication of this paper.

\section{Authors' Contributions}

Weiying Wang wrote, reviewed, and edited the original draft. Songchang Huang was responsible for conceptualization of the study. Yongchun Qin was responsible for resources management. Yiren Sun was responsible for research methodology. Rui Dong was responsible for investigation. Jingyun Chen was involved in supervision and project administration.

\section{Acknowledgments}

This study was sponsored by the National Key R\&D Program of China (2018YFB1600100), China Postdoctoral Science Foundation (2019M650614). Fundamental Research Funds for the Central Research Institutes (2018-9007) and Science and Technology Project of Department of Transportation of Shanxi Province (2018-1-1). The supports are gratefully acknowledged.

\section{References}

[1] National Cooperative Highway Research Program, NCHRP 9-46: Improved Mix Design, Evaluation, and Materials Management Practices for HMA with High RAP Content, TRB and National Research Council, Washington, DC, USA, 2008.

[2] P. S. Kandhal and K. Y. Foo, "Designing recycled hot mix asphalt mixtures using superpave technology," NCAT Report No. 96-5, National Center for Asphalt Technology, Auburn, AL, USA, 1997.

[3] P. S. Kandhal, S. S. Rao, D. E. Watson, and B. Young, "Performance of recycled hot mix asphalt mixtures," NCAT Report No. 95-1, National Center for Asphalt Technology, Auburn, AL, USA, 1995.

[4] R. Mcdaniel and R. M. Anderson, Recommended Use of Reclaimed Asphalt Pavement in the Superpave Mix Design Method: Technician's Manual, NCHRP Report 452, Transportation Research Board of the National Academies, Washington, DC, USA, 2001. 
[5] R. S. McDaniel, H. Soleymani, R. M. Anderson, P. Turner, and R. Peterson, Recommended Use of Reclaimed Asphalt Pavement in the SuperPaveTM Mixture Design Method, NCHRP Final Report (9-12), TRB, National Research Council, Washington, DC, USA, 2000.

[6] Research Institute of Highway Ministry of Transport, Technical Specifications for Highway Asphalt Pavement Recycling, JTG F41-2008, China communication press, Beijing, China, 2008.

[7] S.-J. Lee, S. N. Amirkhanian, N.-W. Park, and K. W. Kim, "Characterization of warm mix asphalt binders containing artificially long-term aged binders," Construction and Building Materials, vol. 23, no. 6, pp. 2371-2379, 2009.

[8] A. Stimilli, G. Ferrotti, C. Conti, G. Tosi, and F. Canestrari, "Chemical and rheological analysis of modified bitumens blended with "artificial reclaimed bitumen"” Construction and Building Materials, vol. 63, pp. 1-10, 2014.

[9] B. Huang, X. Shu, and D. Vukosavljevic, "Laboratory investigation of cracking resistance of hot-mix asphalt field mixtures containing screened reclaimed asphalt pavement," Journal of Materials in Civil Engineering, vol. 23, no. 11, pp. 1535-1543, 2011.

[10] A. Cannone Falchetto, A. Montepara, G. Tebaldi, and M. O. Marasteanu, "Microstructural and rheological investigation of asphalt mixtures containing recycled asphalt materials," Construction and Building Materials, vol. 35, pp. 321-329, 2012.

[11] T. Ma, X. Huang, Y. Zhao, Y. Zhang, and H. Wang, "Influences of preheating temperature of RAP on properties of hotmix recycled asphalt mixture," Journal of Testing and Evaluation, vol. 44, no. 2, 2016.

[12] P. Shirodkar, Y. Mehta, A. Nolan et al., "A study to determine the degree of partial blending of reclaimed asphalt pavement (RAP) binder for high RAP hot mix asphalt," Construction and Building Materials, vol. 25, no. 1, pp. 150-155, 2011.

[13] P. Shirodkar, Y. Mehta, A. Nolan, E. Dubois, D. Reger, and L. McCarthy, "Development of blending chart for different degrees of blending of RAP binder and virgin binder," Resources, Conservation and Recycling, vol. 73, pp. 156-161, 2013.

[14] T. Ma, X. Huang, Y. Zhao, and U. B. Hussain, "Compound rejuvenation of polymer modified asphalt binder," Journal of Wuhan University of Technology-Material Science Education, vol. 25, no. 6, pp. 1070-1076, 2010.

[15] S. Junan, S. Amirkhanian, and J. A. Miller, "Effects of rejuvenating agents on superpave mixtures containing reclaimed asphalt pavement," Journal of Materials in Civil Engineering, vol. 19, no. 5, pp. 376-384, 2007.

[16] X. Yu, M. Zaumanis, S. dos Santos, and L. D. Poulikakos, "Rheological, microscopic, and chemical characterization of the rejuvenating effect on asphalt binders," Fuel, vol. 135, pp. 162-171, 2014.

[17] M. Zaumanis, R. B. Mallick, and R. Frank, "Evaluation of different recycling agents for restoring aged asphalt binder and performance of $100 \%$ recycled asphalt," Materials and Structures, vol. 48, no. 8, pp. 2475-2488, 2014.

[18] J. Jie, S. Zhi, X. Ying, and X. Shifa, "Experimental research on performance of warm-recycled mixture asphalt with SMA," China Journal of Highway and Transport, vol. 26, no. 5, pp. 28-33, 2013.

[19] F. Xiao, X. Hou, S. Amirkhanian, and K. W. Kim, "Superpave evaluation of higher RAP contents using WMA technologies," Construction and Building Materials, vol. 112, pp. 1080-1087, 2016.
[20] R. B. Mallick, P. S. Kandhal, and R. L. Bradbury, "Using warmmix asphalt technology to incorporate high percentage of reclaimed asphalt pavement material in asphalt mixtures, transportation research record," Journal of the Transportation Research Board, vol. 2051, no. 1, pp. 71-79, 2008.

[21] L. Gungat, N. I. M. Yusoff, and M. O. Hamzah, "Effects of RHWMA additive on rheological properties of high amount reclaimed asphalt binders," Construction and Building $\mathrm{Ma}$ terials, vol. 114, pp. 665-672, 2016.

[22] A. Buss, R. C. Williams, and S. Schram, "The influence of warm mix asphalt on binders in mixes that contain recycled asphalt materials," Construction and Building Materials, vol. 77, pp. 50-58, 2015.

[23] M. Tao and R. B. Mallick, "Effects of warm-mix asphalt additives on workability and mechanical properties of reclaimed asphalt pavement material," 2009.

[24] R. West, A. Kvasnak, N. Tran, B. Powell, and P. Turner, "Testing of moderate and high reclaimed asphalt pavement content mixes," Transportation Research Record Journal of the Transportation Research Board, vol. 2126, no. 1, pp. 100-108, 2009.

[25] A. J. d. Barco Carrión, D. Lo Presti, and G. D. Airey, "Binder design of high RAP content hot and warm asphalt mixture wearing courses," Road Materials and Pavement Design, vol. 16, no. sup1, pp. 460-474, 2015.

[26] B. F. Bowers, B. Huang, and X. Shu, "Refining laboratory procedure for artificial RAP: a comparative study," Construction and Building Materials, vol. 52, no. 2, pp. 385-390, 2014.

[27] American Association of State Highway and Transportation Officials, AASHTO R 28, Standard Practice for Accelerate Aging of Asphalt Binder Using a Pressurized Aging Vessel, PAV), Washington, DC, USA, 2012.

[28] American Association of State Highway and Transportation Officials, AASHTO T 240-13, Standard Method of Test for Effect of Heat and Air on a Moving Film of Asphalt (Rolling Thin-Film Oven Test), American Association of State Highway and Transportation Officials, Washington, DC, USA, 2013.

[29] N. I. Md. Yusoff, D. Mounier, G. Marc-Stéphane, M. Rosli Hainin, G. D. Airey, and H. Di Benedetto, "Modelling the rheological properties of bituminous binders using the 2S2P1D Model," Construction and Building Materials, vol. 38, pp. 395-406, 2013.

[30] F. Olard and H. Di Benedetto, "General "2S2P1D" model and relation between the linear viscoelastic behaviours of bituminous binders and mixes," Road Materials and Pavement Design, vol. 4, no. 2, pp. 185-224, 2003.

[31] Y. Sun, B. Huang, J. Chen, X. Jia, and Y. Ding, "Characterizing rheological behavior of asphalt binder over a complete range of pavement service loading frequency and temperature," Construction and Building Materials, vol. 123, pp. 661-672, 2016.

[32] American Association of State Highway and Transportation Officials, AASHTO T 315-08, Standard Method of Test for Determining the Rheological Properties of Asphalt Binder Using a Dynamic Shear Rheometer (DSR), American Association of State Highway and Transportation Officials, Washington, DC, USA, 2012.

[33] L. Wang, J. Wei, and Y. Zhang, "Evaluation on low temperature performance of paving asphalt using bending beam rheometer," Journal of China University of Petroleum, vol. 33, pp. 150-153, 2009.

[34] S. Aflaki and P. Hajikarimi, "Implementing viscoelastic rheological methods to evaluate low temperature 
performance of modified asphalt binders," Construction and Building Materials, vol. 36, pp. 110-118, 2012.

[35] S. Aflaki, P. Hajikarimi, E. H. Fini, and B. Zada, "Comparing effects of biobinder with other asphalt modifiers on lowtemperature characteristics of asphalt," Journal of Materials in Civil Engineering, vol. 26, no. 3, pp. 429-439, 2014.

[36] American Association of State Highway and Transportation Officials, AASHTO T 313-08, Standard Method of Test for Determining the Flexural Creep Stiffness of Asphalt Binder Using the Bending Beam Rheometer (BBR), American Association of State Highway and Transportation Officials, Washington, DC, USA, 2008.

[37] American Association of State Highway and Transportation Officials, AASHTO TP 70-11, Standard Method of Test for Multiple Stress Creep Recovery (MSCR) Test of Asphalt Binder Using a Dynamic Shear Rheometer (DSR), American Association of State Highway and Transportation Officials, Washington, DC, USA, 2011.

[38] Y. Sun, J. Chen, B. Huang, J. Liu, W. Wang, and B. Xu, "Novel procedure for accurately characterizing nonlinear viscoelastic and irrecoverable behaviors of asphalt binders," ASCE's International Journal of Geomechanics, vol. 20, no. 3, Article ID 04019198, 2020.

[39] A. Golalipour, H. U. Bahia, and H. A. Tabatabaee, "Critical considerations toward better implementation of the multiple stress creep and recovery test," Journal of Materials in Civil Engineering, vol. 29, no. 5, 2017.

[40] C. Hintz and H. Bahia, "Simplification of linear amplitude sweep test and specification parameter," Transportation Research Record: Journal of the Transportation Research Board, vol. 2370, no. 1, pp. 10-16, 2013.

[41] M. Huang, X. Wang, and W. Huang, "Analysis of influencing factors for self-healing of fatigue performance of asphalt rubber mixture," China Journal of Highway and Transport, vol. 26, no. 4, pp. 16-22, 2013.

[42] American Association of State Highway and Transportation Officials, AASHTO TP 101-14, Standard Method of Test for Estimating Damage Tolerance of Asphalt Binders Using the Linear Amplitude Sweep, American Association of State Highway and Transportation Officials, Washington, DC, USA, 2014.

[43] C. Hintz, R. Velasquez, C. Johnson, and H. Bahia, "Modification and validation of linear amplitude sweep test for binder fatigue specification," Transportation Research Record: Journal of the Transportation Research Board, vol. 2207, no. 1, pp. 99-106, 2011.

[44] Y. Sun, W. Wang, and J. Chen, "Investigating impacts of warm-mix asphalt technologies and high reclaimed asphalt pavement binder content on rutting and fatigue performance of asphalt binder through MSCR and LAS tests," Journal of Cleaner Production, vol. 219, pp. 879-893, 2019.

[45] M. Sadeq, E. Masad, H. Al-Khalid, O. Sirin, and L. Mehrez, "Linear and nonlinear viscoelastic and viscoplastic analysis of asphalt binders with warm mix asphalt additives," International Journal of Pavement Engineering, vol. 19, no. 10, pp. 857-864, 2016.

[46] C. M. Johnson, H. Wen, and H. U. Bahia, "Practical application of viscoelastic continuum damage theory to asphalt binder fatigue characterization," in Proceedings of the Asphalt Paving Technology: Association of Asphalt Paving Technologists-Proceedings of the Technical Sessions, pp. 597-631, Bangkok, Thailand, December 2009.

[47] D. Singh, P. K. Ashish, A. Kataware, and A. Habal, "Evaluating performance of PPA-and-elvaloy-modified binder containing
WMA additives and lime using MSCR and LAS tests," Journal of Materials in Civil Engineering, vol. 29, no. 8, 2017.

[48] J. Xiaoyang, H. Baoshan, B. F. Bowers, and Z. Sheng, "Infrared spectra and rheological properties of asphalt cement containing waste engine oil residues," Construction and Building Materials, vol. 50, pp. 683-691, 2014.

[49] P. K. Ashish, D. Singh, and S. Bohm, "Investigation on influence of nanoclay addition on rheological performance of asphalt binder," Road Materials and Pavement Design, vol. 18, no. 5, pp. 1007-1026, 2016.

[50] R. Micaelo, A. Pereira, L. Quaresma, and M. T. Cidade, "Fatigue resistance of asphalt binders: assessment of the analysis methods in strain-controlled tests," Construction and Building Materials, vol. 98, pp. 703-712, 2015.

[51] American Society of Testing Materials, ASTM D7460-10, Standard Test Method for Determining Fatigue Failure of Compacted Asphalt Concrete Subjected to Repeated Flexural Bending, ASTM International, West Conshohocken PA, USA, 2010. 